University of Nebraska - Lincoln

DigitalCommons@University of Nebraska - Lincoln

Papers in the Earth and Atmospheric Sciences

Earth and Atmospheric Sciences, Department

1997

\title{
Relations between Directional Spectral Vegetation Indices and Leaf Area and Absorbed Radiation in Alfalfa
}

\author{
Elizabeth Walter-Shea \\ University of Nebraska-Lincoln, ewalter-shea1@unl.edu \\ Jeffrey L. Privette \\ NASA Goddard Space Flight Center \\ D. Cornell \\ U.S. Air Force \\ Mark A. Mesarch \\ University of Nebraska-Lincoln, mmesarch1@unl.edu \\ C. Hays \\ University of Nebraska-Lincoln, chays1@unl.edu
}

Follow this and additional works at: https://digitalcommons.unl.edu/geosciencefacpub

Part of the Earth Sciences Commons

\footnotetext{
Walter-Shea, Elizabeth; Privette, Jeffrey L.; Cornell, D.; Mesarch, Mark A.; and Hays, C., "Relations between Directional Spectral Vegetation Indices and Leaf Area and Absorbed Radiation in Alfalfa" (1997). Papers in the Earth and Atmospheric Sciences. 411.

https://digitalcommons.unl.edu/geosciencefacpub/411
}

This Article is brought to you for free and open access by the Earth and Atmospheric Sciences, Department of at DigitalCommons@University of Nebraska - Lincoln. It has been accepted for inclusion in Papers in the Earth and Atmospheric Sciences by an authorized administrator of DigitalCommons@University of Nebraska - Lincoln. 


\title{
Relations between Directional Spectral Vegetation Indices and Leaf Area and Absorbed Radiation in Alfalfa ${ }^{1}$
}

\author{
E. A. Walter-Shea, J. Privette ${ }^{\dagger}$ D. Cornell,$\ddagger$ M. A. Mesarch ${ }^{\dagger}$ \\ and C. J. Hays
}

$S$ on satellite platforms with extreme view angles have been increasingly used to analyze regional and global vegetation cover and productivity because of frequent observations. This study, using experimental and theoretical methods, analyzed variations in vegetation indices with sun-view geometry as a means of understanding the sensitivity of relations beween vegetation indices and the biophysical properties, the leaf area index (LAI), and the instantaneous fraction of absorbed photosynthetically active radiation (fAPAR). Canopy bidirectional reflectance factors (BRFs) of an alfalfa crop were measured and simulated at a variety of solar and view zenith angles. Also, fAPAR, LAI, and leaf optical properties were measured. Measured and simulated canopy reflectances agreed generally within $1 \%$ (absolute). Normalized difference and simple ratio vegetation indices (NDVI and $S R V I$, respectively), derived from BRFs, varied with view and solar zenith angles. The minimum for near-infrared (NIR) BRFs and relatively high red BRFs generally occurred near nadir, resulting in some of the lowest vegetation index values. Highest VI values were generally obtained at forward view angles. Variation of NDVI with sun-view-geometry was greatest at LAIs $<2$, whereas the range in SRVI was greatest for LAIs $>2$. Measured reflectances indicate that relations between NDVI and LAI and between SRVI and FAPAR were curvilinear across all solar and view zenith angle combinations in the solar

${ }^{1}$ Published as Paper No. 10585, J. Ser., Nebraska Agric. Res. Div. 'Department of Agricultural Meteorology, University of $\mathrm{Ne}$ braska, Lincoln

†NASA Goddard Space Flight Center, Greenbelt

$\$$ Currently with the U.S. Air Force, Mt. Home AFB, Idaho

Address correspondence to Dr. E. A. Walter-Shea, Dept. of Agric. Meteorol, Univ of Nebraska, Lincoln, NE 68583-0798.

Received 15 August 1996; revised 25 November 1996. principal plane, whereas relations between SRVI and LAI and between NDVI and FAPAR varied from linear to curvilinear. Analyses revealed that vegetation indices at large view zenith angles were poorly correlated with fAPAR, whereas those at small zenith angles were strongly correlated. In general, vegetation indices were more sensitive to fAPAR than to LAI, which is attributed to the fact that fAPAR is a radiation quantity, whereas LAI is nonlinearly related to radiation. Regression of fAPAR with VI values derived from combinations of red and NIR BRFs from similar and nonsimilar directions indicates that the highest correlation is in near-nadir and backscatter directions. However, further investigation into variations of relations between remotely sensed observations and canopy attributes and into the usefulness of off-nadir in extracting information is recommended. (C) Elsevier Science Inc., 1997

\section{INTRODUCTION}

The usefulness of remotely sensed data depends on consistency of relations between detected radiation and biophysical processes. Factors affecting the amount of radiation reflected from a vegetative surface and received by a remote sensing device include leaf optical properties, underlying background, solar angle, atmospheric condition, sensor view angle, and canopy geometry (Norman et al., 1985). Reflected irradiation and biophysical processes, such as fraction of ground cover, wet and dry biomass, leaf area index (LAI), plant water content, and the fraction of absorbed photosynthetically active radiation (fAPAR) (Holben et al., 1980; Tucker 1979), have been related to vegetation indices (combinations of spectral bands). Two commonly used vegetation indices are the 


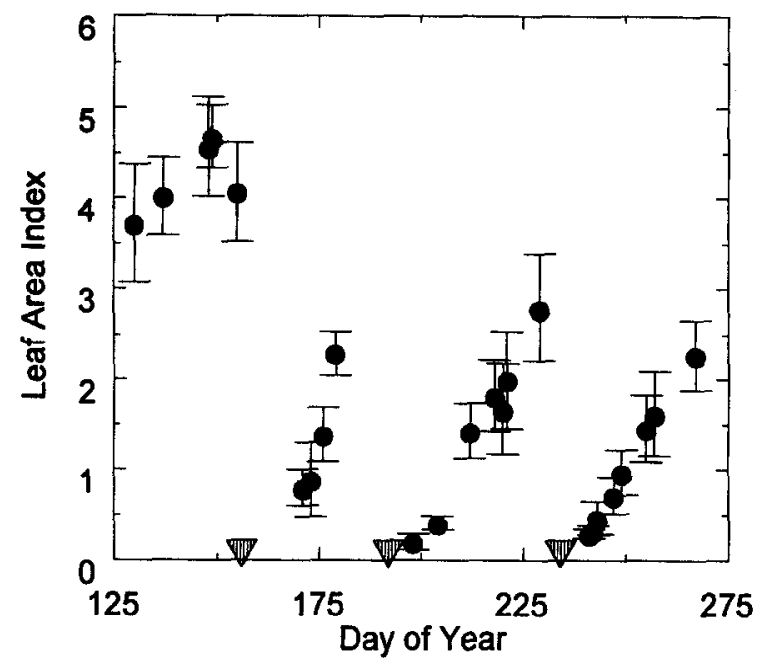

Figure 1. Mean LAI during measurement period from DOY 125 (5 May) to DOY 275 (2 October 1990).

Means are from four plots with error bars indicating

\pm 1 standard deviation. Arrows indicate alfalfa cutting dates.

simple ratio vegetation index (SRVI), defined by NIR/R in which NIR and R designate the energy reflected in the near-infrared and red portions of the electromagnetic spectrum, and the normalized difference vegetation index (NDVI), defined by (NIR-R)/(NIR+R).

The relation between NDVI and LAI has been shown to be more nonlinear than that between SRVI and LAI (Holben et al., 1980). Relations between vegetation indices and fAPAR can be linear (Kumar and Monteith, 1981) or nonlinear (Asrar et al., 1984; Choudhury, 1987; Sellers, 1985), including exponential (Steven et al., 1983) and quadratic (Gallo et al., 1985). Several regional and global models utilize the simple relations between spectral indices, fAPAR, LAI, and photosynthesis to simulate photosynthesis or evapotranspiration or both (Bonan, 1995).

Most of the published relations between vegetation indices and biophysical parameters were derived from measured or simulated data viewed at nadir as limited solid angle segments or hemispherically. However, the relations have been shown to be sensitive to a variety of factors including canopy geometry (Jackson and Pinter, 1986), background (Huete et al., 1985), solar and view zenith angles (Deering et al., 1992; Ranson et al., 1985; Walter-Shea et al., 1992). Regional and global vegetation analysis have utilized data from the advanced very high resolution radiometer (AVHRR) aboard the National Oceanic and Atmospheric Administration (NOAA) series of satellites because its $112^{\circ}$ view span permits daily observations. Because commonly used vegetation indices vary as a function of viewing geometry (Asrar et al., 1992; Deering and Middleton, 1990; Shibayama et al., 1986; Wardley, 1984), relations between these vegetation indices and biophysical paramcters also vary as a function of

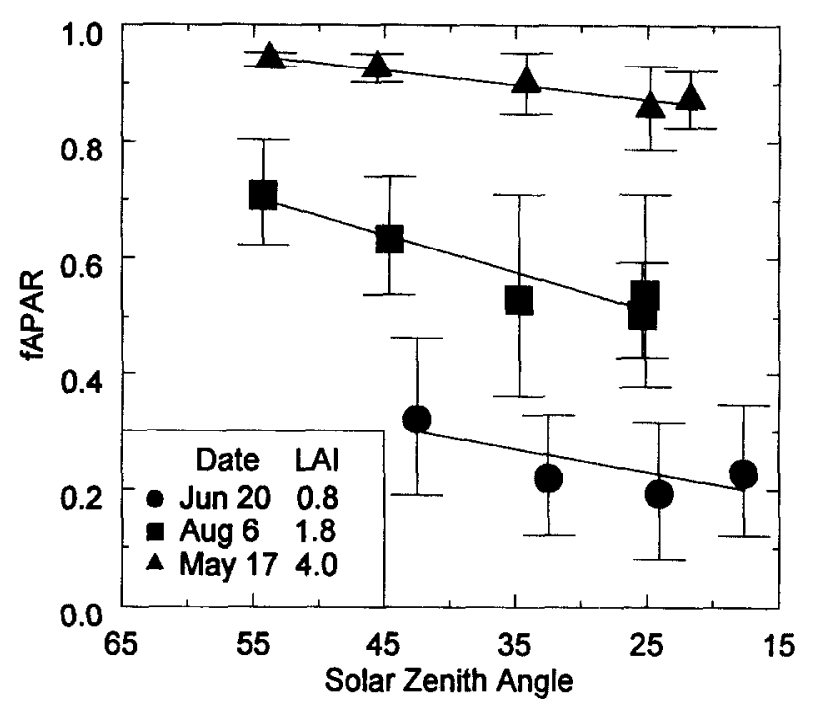

Figure 2. fAPAR as a function of solar zenith angle for three representative days of the measurement period: DOY 137 (17 May), DOY 171 (20 June) and DOY 218 (6 August). Means are from four plots with error bars indicating \pm 1 standard deviation.

viewing geometry (Epiphanio and Huete, 1995; Roujean and Breon, 1995). For example, a linear relation between nadir-derived NDVI and fAPAR varied by $10-15 \%$ over a range of solar zenith angles and plant canopy geometries (Asrar et al., 1992); fAPAR and NDVI change in a similar manner with solar zenith angle (Bartlett et al., 1990; Middleton, 1991; Pinter, 1993). Simulations indicate that off-nadir vegetation indices can also be nonlinearly related to fAPAR (Asrar et al., 1992). An ideal vegetation index would simultaneously retain maximum sensitivity to crop characteristics and be relatively unaffected by solar angle, atmospheric turbidity, topography, and viewing direction (Pinter et al., 1987). Some research has been directed at producing a vegetation index approaching those ideals (Chehbouni et al., 1994; Huete, 1992). Recently, Sellers et al. (1994) introduced a procedure using an empirical temporal filtering to reduce variations due to sun angle, atmospheric effects, and background reflectance. Goward and Huemmrich (1992) suggest exploring canopy bidirectional reflectance domains. Others have recommended restricting data to $\pm 14^{\circ}$ of nadir as a means of reducing variability in vegetation indices from NOAA-AVHRR data (Duggin et al., 1982). Three research groups identified by Sellers et al., (1990) discard data obtained at extreme view angles to reduce directional effects, but apparently none of the groups routinely correct data for effects due to solar zenith angle or atmospheric path length. A $\pm 25^{\circ}$ off nadir, restriction has been applied to data used in a global inventory monitoring and modeling studies group at NASA (Gutman, 1991). However, by restricting the viewing angles, potentially useful information in off-nadir obser- 
a)
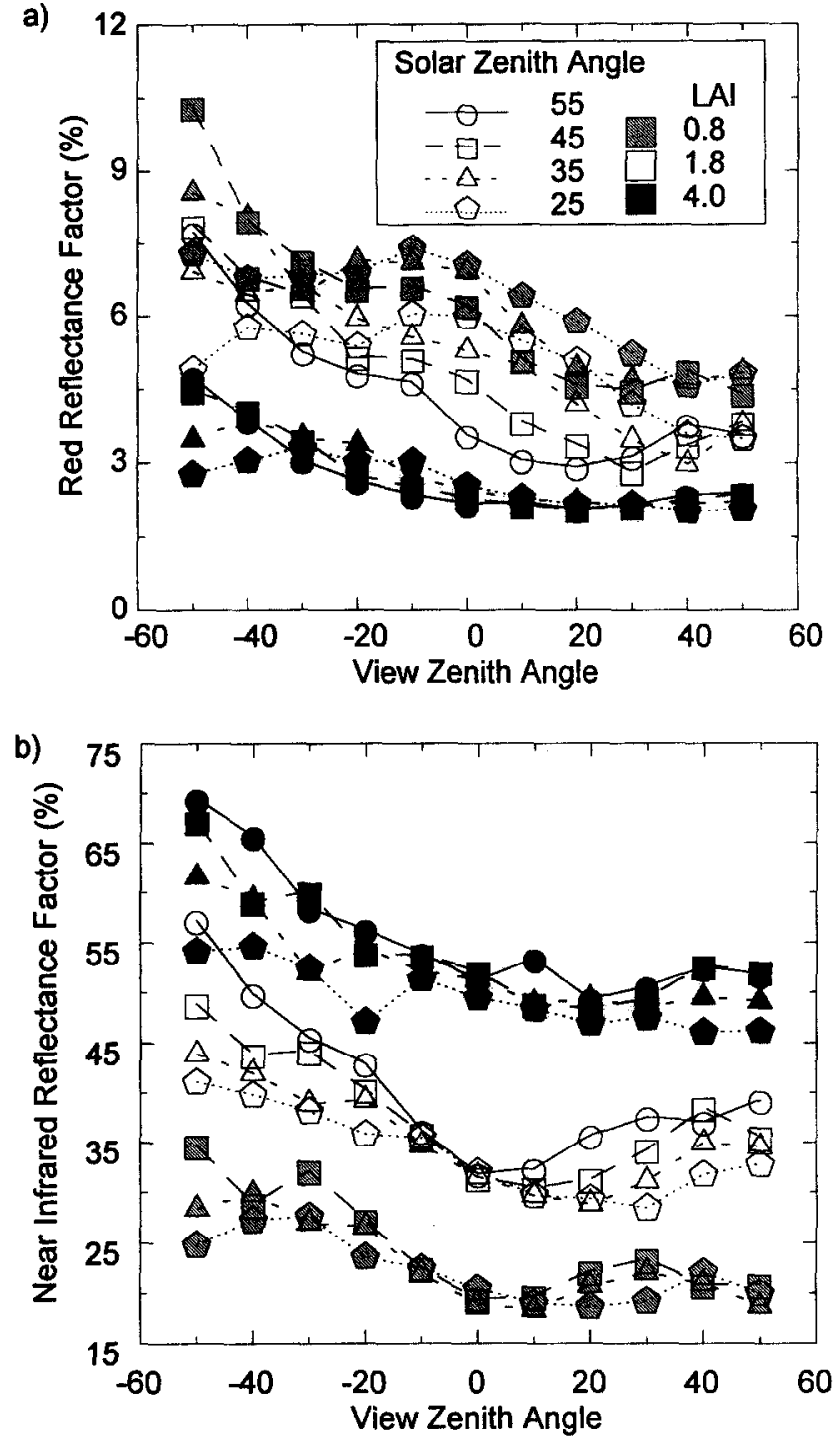

Figure 3. Canopy bidirectional reflectance factors (BRFs) (expressed in \%) as a function of solar and view zenith angles for three representative days of the measurement period: (a) MMR wave-band 3 reflectance $(630-690 \mathrm{~nm})$; (b) MMR wave-band 4 reflectance $(760-900 \mathrm{~nm})$. Positive view zenith angles represent forward scatter direction; negative view zenith angles represent backscatter direction. Data points represent the mean of four plots.

vations may be ignored (Gutman, 1991). Moreover, the temporal frequency of sampling is reduced.

Before exploring the BRF domain, we must understand the sensitivity of relations of vegetation index with biophysical parameters so that observations over a broad range of viewing conditions can be understood and described mathematically. The accuracy of estimating LAI using NDVI and SRVI (and other vegetation indices) was addressed for nadir VI by using measured and simulated data; results for simulated data indicated that the relations were most sensitive to leaf color (Bouman, 1992).
Experiments have also been conducted to investigate the sensitivity to sensor-target geometry with a prairie ecosystem by using helicopter-retrieved data (Brown de Coulston et al., 1995) and in alfalfa (Epiphanio and Huete, 1995). The objective of our study was to gain an understanding of the sensitivity of relations between two commonly used vegetation indices (SRVI and NDVI), with LAI and fAPAR of a developing alfalfa canopy under a variety of solar and view zenith angle conditions. Measured and simulated data were used to elucidate general trends in the data and their general applicability to a variety of vegetated surfaces and conditions. Observed VI values were smoothed to determine the general relation of VI values to LAI and fAPAR, and the simulated VI values were used to deternine how well these relations could be described with simple equations and how they varied with view angle.

\section{MATERIALS AND METHODS}

\section{Field Experiment}

Field work was conducted at the University of Nebraska Agriculture Research and Development Center near Mead, Nebraska $\left(41^{\circ} 09^{\prime} \mathrm{N}, 96^{\circ} 30^{\prime} \mathrm{W}, 354 \mathrm{~m}\right.$ above mean sea level) in an irrigated alfalfa (Medicago sativa L.) field in 1990 from 10 May through 24 September. Multispectral bidirectional reflectance factors (BRFs), fAPAR, and various canopy and soil parameters were measured.

Experimental plots were established in a 2.8-ha stand of 'Perry' alfalfa planted on 21 April 1988; the field was well established with the north-south drill row structure not readily evident. The soil was a Sharpsburg silty clay loam. Four plots aligned in an east-west direction were selected on the basis of visually determined canopy uniformity. Alfalfa is a diaheliotropic plant, meaning that most of its leaflets are aligned in the solar principal plane, particularly at large solar zenith angles, but parallel to the beam at smaller solar zenith angles, with very little diurnal change occurring in leaflet zenith angle (Travis and Reed, 1983).

\section{Reflectance Factor Measurements}

Canopy BRFs were derived from reflected radiation measured over canopy and reference panel targets with a Barnes 12-1000 modular multiband radiometer (MMR)* and recorded on a Polycorder (Omnidata International Inc., Logan, UT) during 16 days of the experimental period. The MMR produces a voltage proportional to scene radi-

\footnotetext{
- The use of company names and brand names is necessary to report factually on available data; however, the University of Nebraska and USAF neither guarantee nor warrant the standard of the product, and the use of the name by the University of Nebraska and USAF implies no approval of the product to the exclusion of others that also may be suitable.
} 
a)

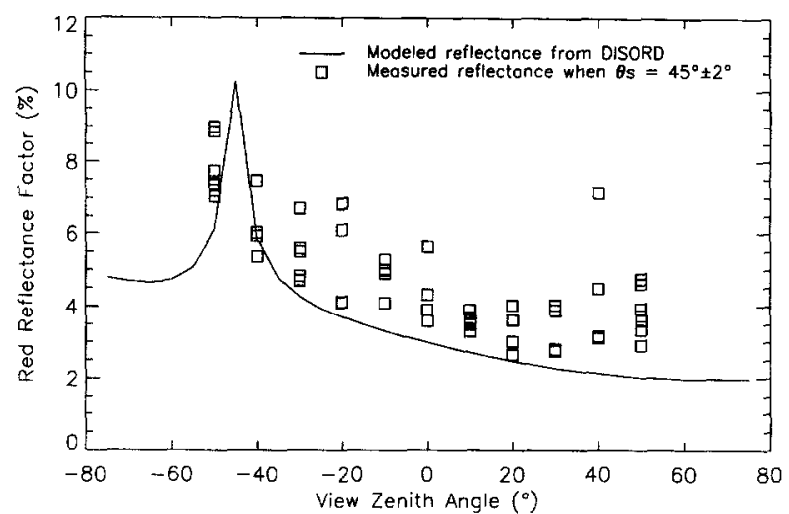

b)

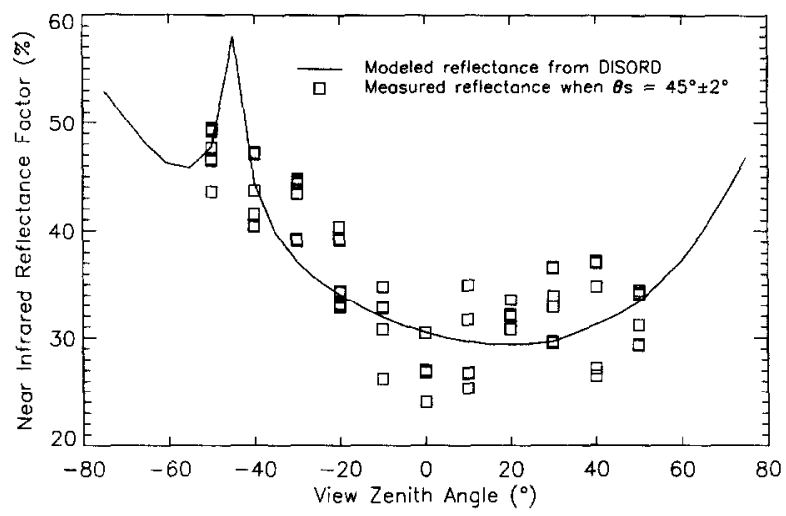

Figure 4. Comparison of measured and simulated BRFs in the solar principal plane for DOY 176. The model was configured with field-measured parameter values (LAI was 1.4), and field-measured reflectance occurred when solar zenith angle was within two degrees of 45 . (a) Reflectance for MMR band 3 (red). (b) MMR band 4 (NIR).

ance in seven reflective wavelength bands: (1) 450-520, (2) $520-600$, (3) $630-690$, (4) $760-900,(5), 1150-1300$, (6) $1550-1750$, and (7) $2080-2350 \mathrm{~nm}$. The radiometer was set with a $15^{\circ}$ field of view and attached to a pivoting extension mounted on a 3-m aluminum mast. The pivoting extension allowed MMR orientation at view zenith angles $\left(\theta_{v}\right)$ ranging from $+50^{\circ}$ (forward-scatter direction) to $-50^{\circ}$ (backscatter direction) in the solar principal plane at $10^{\circ}$ intervals. Shadow contamination from the instrument in the hot spot was not corrected in the readings. The vegetative area viewed at each view zenith angle varied in shape and size; the footprint at ground level was $0.5 \mathrm{~m}^{2}$ at a nadir view and $1.9 \mathrm{~m}^{2}$ for a $\theta_{v}$ equal to $\pm 50^{\circ}$.

Data were collected at a solar zenith angle $\left(\theta_{s}\right)$ of $55^{\circ}$ through solar noon (18-43 $3^{\circ}$ depending on the date) at $10^{\circ}$ increments. The number of solar zenith angles represented on a given day was a function of sky condition and time of year. Measurements were taken only when no clouds were within approximately $20^{\circ}$ of the solar disk. Canopy reflected radiation was measured three times for each view direction from which a mean value

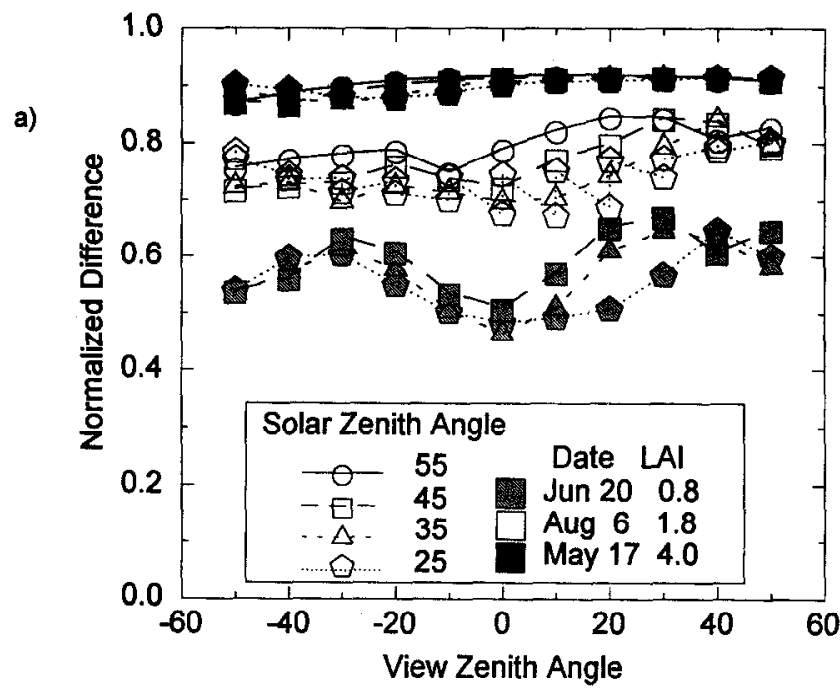

b)

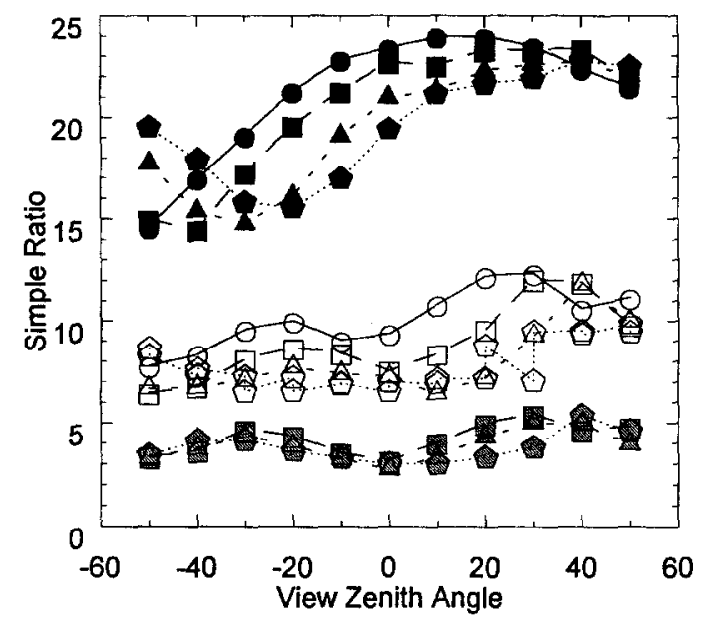

Figure 5. Vegetation indices as functions of solar and view zenith angles for three representative days of the measurement period: (a) normalized difference; (b) simple ratio. Data points represent the mean of four plots.

was calculated. Each BRF measurement sequence required between 15 and $20 \mathrm{~min}$ to complete (the greatest change in solar zenith angle during this time was $2.8^{\circ}$, actual $\theta_{s}$, varied on average by $0.6^{\circ}$ from the reported nominal $\theta_{s}$ ).

Canopy spectral measurements were expressed as BRFs to correct for irradiance differences and to facilitate comparison within and among dates. The BRF (expressed in \%) is defined as the ratio of the radiant flux density reflected by the canopy to the radiant flux density that would be reflected from a lossless Lambertian surface illuminated and viewed in the same manner as the canopy (Nicodemus et al., 1977). Nadir-viewed reflected radiation (output voltage) measured over a calibrated 1.2 $\mathrm{m} \times 1.2 \mathrm{~m}$ molded sintered polytetrafluorethylene-based (Spectralon) panel (Labsphere Inc., North Sutton, NH) was used as an estimate of radiance from a Lambertian 
a)

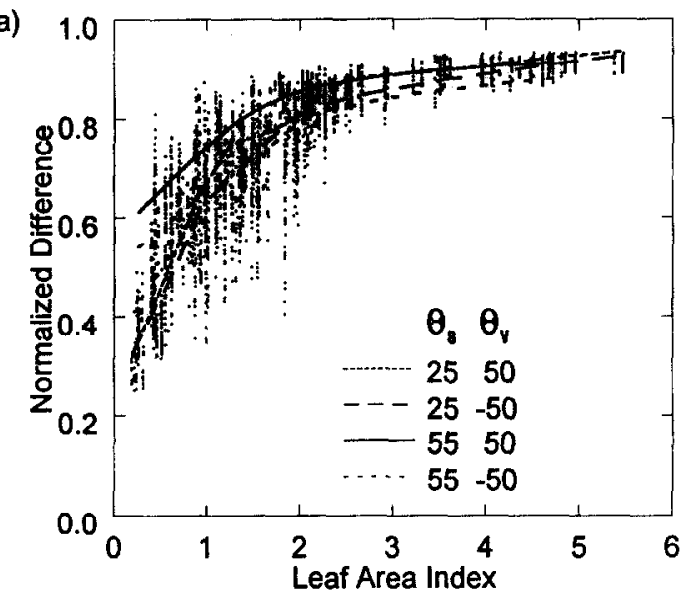

b)

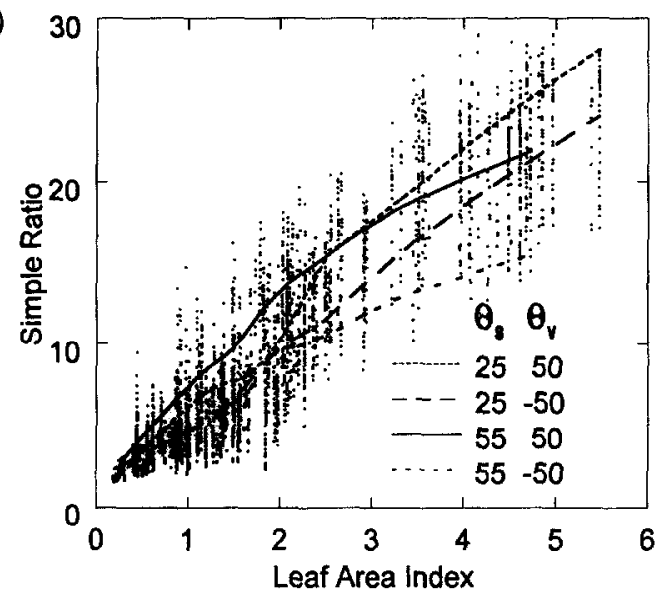

Figure 6. Vegetation indices derived from measured BRFs over a developing alfalfa canopy over the measurement period characterized as functions of LAI. General trends in the data are shown with smoothed data lines from data measured at the specified $\theta_{\mathrm{s}}$ and $\theta_{\mathrm{v}}$ and indicate the bounds of the data set. (a) Normalized difference. (b) Simple ratio.

surface; the panel was calibrated to correct for non-Lambertian properties in accord with the technique of Jackson ct al. (1987) and Walter-Shea ct al. (1993). Thus, the BRF for each spectral band was calculated as the ratio of output voltage over the canopy to the output voltage measured at nadir over the panel (and expressed in \%). A time-based linear interpolation was used to estimate the nadir signal of the reference panel at the time of individual canopy measurements (Robinson and Biehl, 1979).

\section{fAPAR MEASUREMENTS}

Fractions of instantaneously absorbed PAR (fAPAR) were calculated from measurements made immediately following MMR measurements with an LI-191SA line quantum sensor (LI-COR, Lincoln, NE) in perpendicular alignment with the solar principal plane. FAPAR was calculated from three sets of measurements for each plot as:
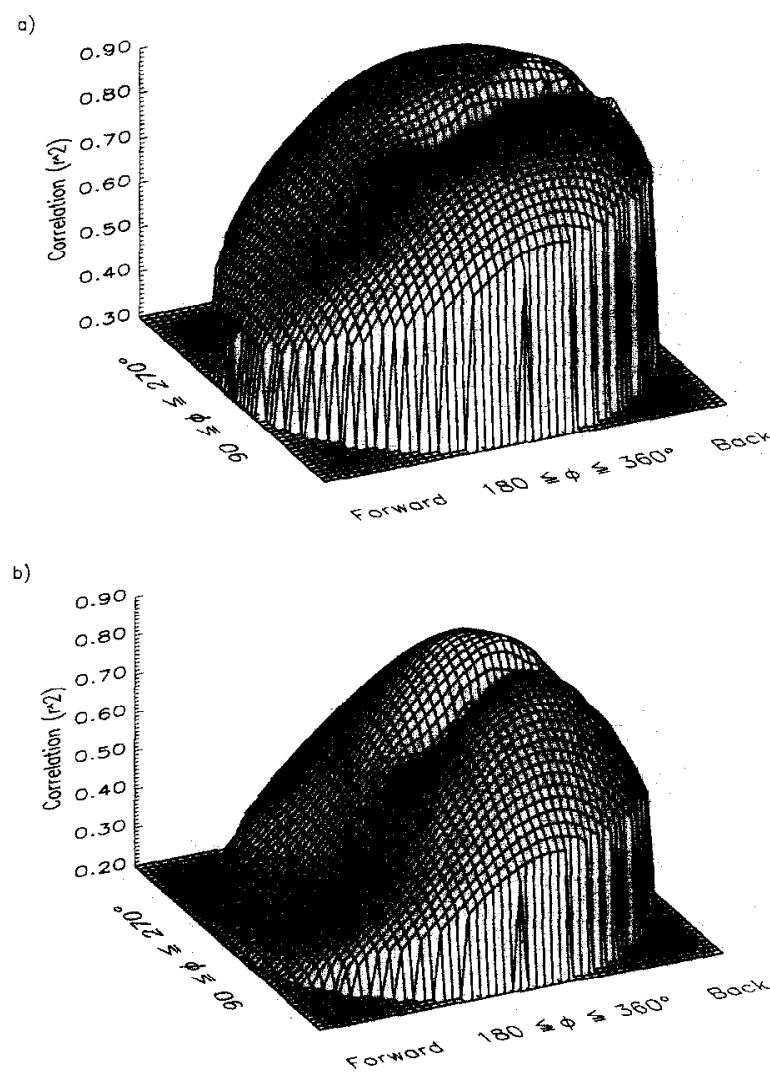

Figure 7. Correlation coefficient $\left(r^{2}\right)$ of vegetation indices calculated from simulated BRFs with LAI as a function of viewing geometry. View zenith angles increase from the center (nadir) outward to the edge $\left(75^{\circ}\right)$. The backscatter angles are toward the right. For each view angle; LAI varied between 0.5 and 5.0 by intervals of 0.25 , the solar angle varied between $0^{\circ}$ and $65^{\circ}$ by $5^{\circ}$ intervals; and the leaf angle distribution varied between erectophile and planophile. All combinations were used for each regression.

(a) NDVI vs $\ln (\mathrm{LAl})$. (b) SRVI vs LAI.

$$
\text { fAPAR }=\left[(\text { PAR }- \text { TPAR })-\left(\text { RPAR }_{c}-\text { TRPAR }_{s}\right)\right] / \text { PAR, }
$$

where PAR is PAR irradiance measured with the sensor in an upright position about $0.5 \mathrm{~m}$ above the canopy, TPAR is canopy transmitted PAR measured with the sensor inserted in the canopy in an upright position at the soil surface, $\mathbf{R P A R}_{c}$ is canopy reflected PAR measured with the sensor inverted over the canopy at the same height as the incident PAR measurement, and TRPAR $_{s}$ is transmitted PAR that is reflected from the soil surface measured with the sensor inserted under the canopy but inverted approximately $5 \mathrm{~cm}$ above the soil surface (with the assumption that the contribution of shading from the instrument is negligible).

\section{Leaflet Optical Measurements}

Leaflet PAR reflectances and transmittances were determined from reflected and transmitted PAR measurements by using a LI-COR LI-1800-12 integrating sphere equipped with an LI-190SA quantum sensor that mea- 


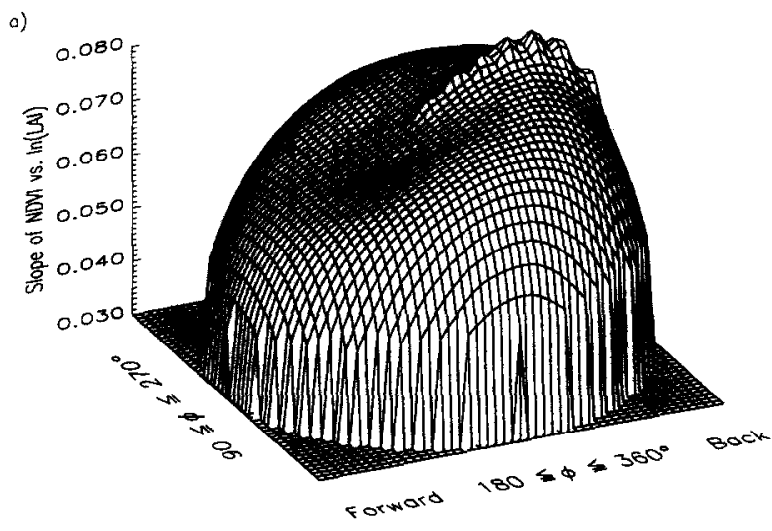

b)

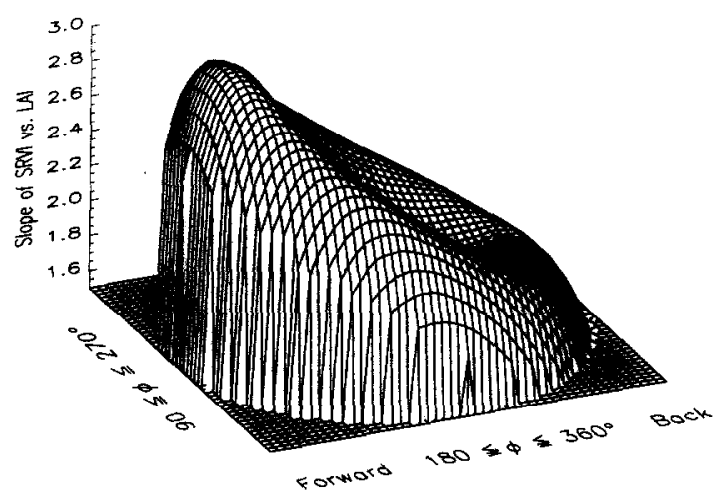

Figure 8. Sensitivity of the simulated vegetation indices with LAI as a function of viewing geometry. The sensitivity is indicated by the slopes of the regression lines. View zenith angles increase from the center (nadir) outward to the edge $\left(75^{\circ}\right)$. The backscatter angles are toward the right. For each view angle, LAI varied between 0.5 and 5.0 hy intervals of 0.25 , the solar angle varied between $0^{\circ}$ and $65^{\circ}$ by $5^{\circ}$ intervals, and the leaf angle distribution varied between erectophile and planophile. (a) NDVI vs $\ln (\mathrm{LAI})$. (b) SRVI vs LAI.

sures over the 400-700-nm wavelength range. Voltage output was recorded on a Polycorder (Omnidata International Inc., Logan, Utah). Adaxial and abaxial alfalfa leaflet PAR optical properties were measured from upper and lower canopy portions. Spectral leaf reflectances and transmittances were measured on 23 September, 1990 over the wavelength range of 400 to $1000 \mathrm{~nm}$ at approximately 3-nm intervals, with a Spectron Engineering SE590 spectroradiometer as a means of documenting spectral contributions to the PAR and NIR values.

\section{Agronomic Measurements}

Agronomic measurements included LAI, mean tilt angle, and soil moisture. LAI and mean tilt angle were retrieved from measurements of incident and transmitted "blue" light (radiation at wavelengths less than $490 \mathrm{~nm}$ ) through the alfalfa canopy by using a LAI 2000 plant canopy analyzer (LI-COR, Lincoln, NE) (Welles and Norman, 1991). Incident and transmitted blue light were measured after every BRF measurcment sequence with
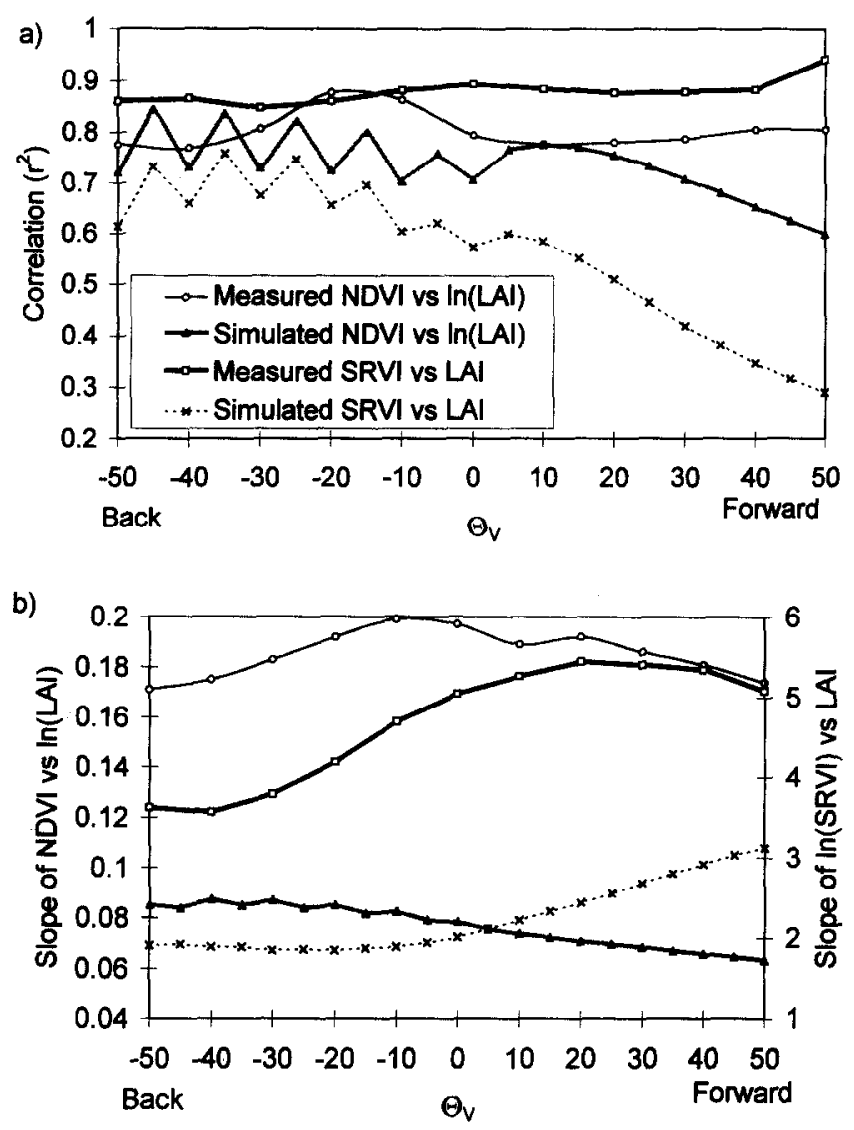

Figure 9. Regression results for NDVI vs $\ln (\mathrm{LAI})$ and SRVI vs LAI calculated from measured BRFs and simulation results (from Figs. 7 and 8) as a function of viewing gcometry in the solar principal plan. View zenith angles range from nadir to $50^{\circ}$ in the backscatter and forward scatter directions. For each view angle for measured BRI values, LAI varied between 0.4 and 4.7 , and the solar angle varied between $18^{\circ}$ and $55^{\circ}$. All combinations were used for each regression. (a) Correlation coefficients $\left(r^{2}\right)$. (b) Slopes.

a $90^{\circ}$ view restrictor placed on the LAI-2000 lens. Mean tilt angle was retrieved from all gap fractions measured when the canopy was not shaded because direct sunlight does not affect the mean tilt angle estimation (LAI-2000 instruction manual). I.AI was estimated from gap fractions measured when a part of each alfalfa plot was shaded with a $0.9 \mathrm{~m} \times 0.6 \mathrm{~m}$ board to meet the diffuse lighting requirement for proper LAI-2000 use in retrieving LAI estimates. Soil moisture was estimated gravimetrically from three 0.15 -m-long soil cores centered at $0.15,0.45$, and $0.76 \mathrm{~m}$ depths north of each plot. Additionally, soil surface color was characterized with the Munsell color chips (Munsell Soil Color Chart, Macbeth Division of Kollmorgen Inst. Corp., Baltimore, MD) in each plot at midmorning and solar noon.

\section{Model Description}

A numerical turbid medium model, DISORD (Myneni et al., 1992) was uscd to model the reflectance from a 

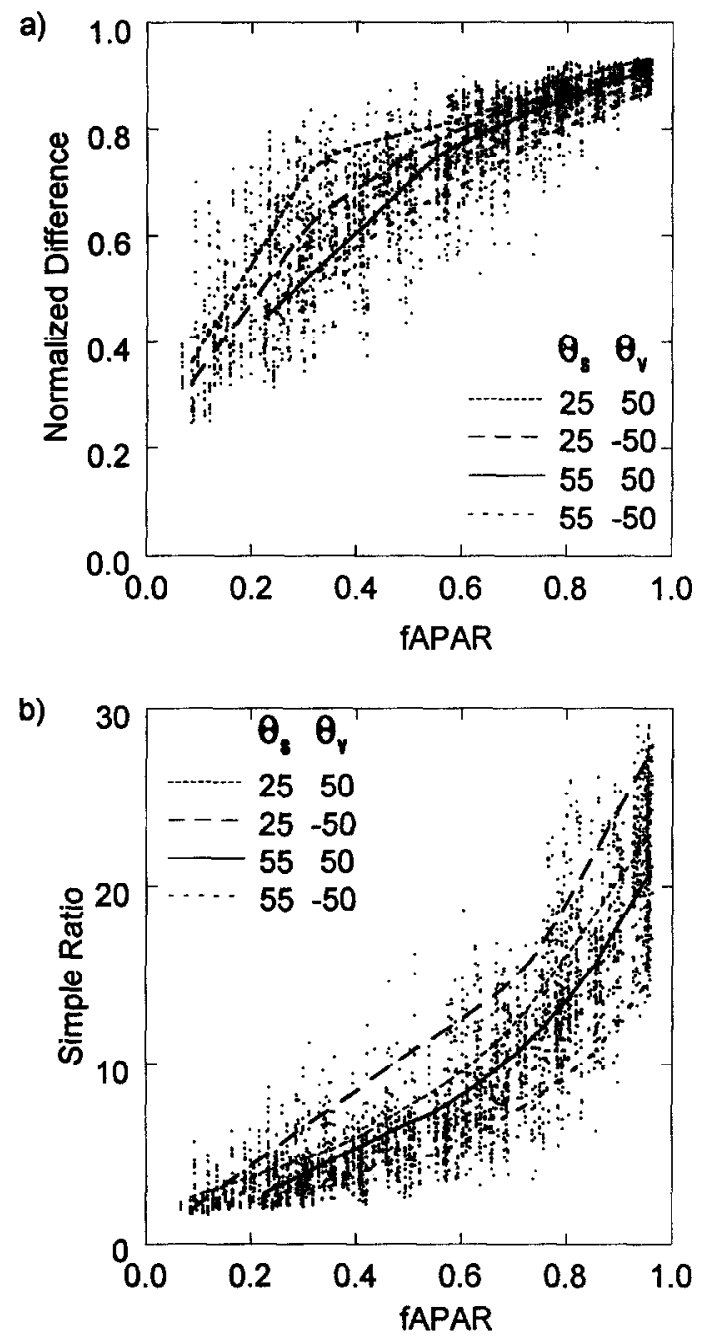

Figure 10. Vegetation indices derived from measured BRFs over a developing alfalfa canopy over the measurement period characterized as functions of fAPAR. General trends in the data are indicated with smoothed data lines from data measured at the specified $\theta_{s}$ and $\theta_{v}$ and indicate the bounds of the entire data set. (a) Normalized difference. (b) Simple ratio.

canopy simulated as a horizontal cloud of infinitesimal leaflets positioned randomly in space (Ross, 1981). Canopy depth is specified through the LAI parameter, and leaf angle distribution is described with a beta distribution (Goel and Strebel, 1984). Leaf scattering anisotropy is simulated by combining diffuse and specular phase functions. A canopy hot spot approximation also is included with the hot spot parameter fixed to a typical value (Stewart, 1991). The transport equation is solved by using the discrete ordinates method. Anisotropic soil reflectance is simulated by using the six-parameter SOILSPECT model (Jacquemoud et al., 1992).

To simulate the alfalfa reflectance, DISORD parameters were fixed with values measured at the alfalfa test site. Downwelling irradiance was specified as the sum of

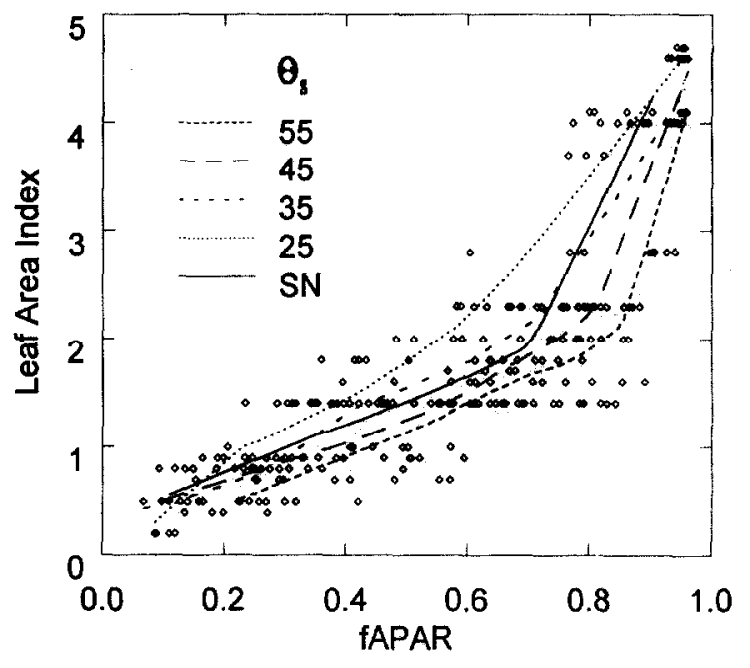

Figure 11. fAPAR measured from a developing alfalfa canopy at various sun geometries over the measurement period characterized by LAI. General trends in the data are shown by smoothed data lines from data measured at the specified $\theta_{\mathrm{s}}$ and $\theta_{\mathrm{v}}$ and indicate the bounds of the entire data set.

direct and isotropic diffuse components; typical ratios of these quantities for MMR bands were taken from Privette et al. (1995). Leaflet optical properties were fixed throughout the simulations on the basis of integrated spectral reflectance and transmittances from the SE-590. SOILSPECT parameters for the simulation were derived in an inversion procedure (Privette et al., 1995) by using bare soil reflectance data collected before the alfalfa crop developed; the mean retrieved soil parameter values were fixed for all subsequent modeling. Horizontal homogeneity (one-dimensionality problem) was assumed.

\section{Analysis}

The field experiment was designed so that canopy reflectance was measured at solar zenith angles $\left(\theta_{s} s\right)$ of solar noon, $25^{\circ}, 35^{\circ}, 45^{\circ}$, and $55^{\circ}$ and at view zenith angles $\left(\theta_{\mathrm{r}} \mathrm{s}\right)$ of $\pm 50^{\circ}, \pm 10^{\circ}, \pm 30^{\circ}, \pm 20^{\circ}, \pm 10^{\circ}$, and $0^{\circ}$, where a plus sign indicates view angles in the forward scatter direction and a minus sign indicates view angles in the backscatter direction. NDVI and SRVI were calculated for all view and solar angle combinations.

General trends in the measured canopy reflectance data were indicated through a data smoothing technique that uses $x$ values (NDVI or SRVI) to find predicted values from a weighted average of nearby $y$ values (LAI or fAPAR) (SYSTAT Inc., Evanston, IL 60201-3793). The smoothing technique weights points close to a particular $(x, y)$ location more heavily than points far away to predict the $y$ on the smoothed fitted line. Variability in relations between vegetation indices derived from measured canopy reflectances at various $\theta_{s}, \theta_{i}, \mathrm{LAl}$, and fAPAR was investigated through comparisons of smoothed data lines 

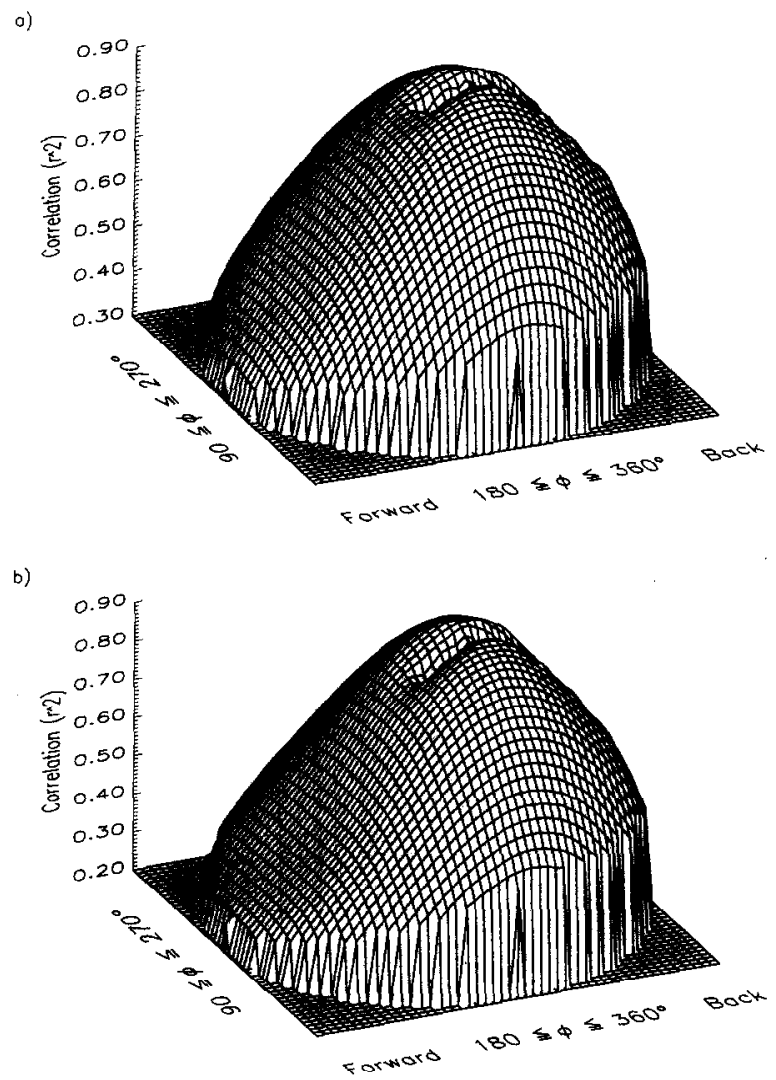

Figure 12. Correlation coefficient $\left(r^{2}\right)$ of vegetation indices calculated from simulated BRFs and fAPAR as a function of viewing geometry. View zenith angles increase from the center (nadir) outward to the edge $\left(75^{\circ}\right)$. The backscatter angles are toward the right. For each view angle, LAI varied between 0.5 and 5.0 by intervals of 0.25 , the solar angle varied between $0^{\circ}$ and $65^{\circ}$ by $5^{\circ}$ intervals, and the leaf angle distribution varied between erectophile and planophile. (a) NDVI vs fAPAR. (b) $\ln$ (SRVI) vs fAPAR. Absorbed red radiation was used as a surrogate for fAPAR.

representing the trends for each illumination/view condition.

With the use of DISORD, bidirectional reflectances were simulated, at every $5^{\circ}$ in view zenith angle between $0^{\circ}$ and $75^{\circ}$, and at every $15^{\circ}$ in azimuth angle between $0^{\circ}$ and $180^{\circ}$ (within unit steradian solid angle while the MMR has a $15^{\circ}$ IFOV), for canopies with erectophile or planophile leaf angle distribution and LAIs of 1,3 , and 5 . The solar zenith angle was varied at $5^{\circ}$ increments between $0^{\circ}$ and $65^{\circ}$. For each combination of canopy parameters and solar angle, NDVI, SRVI, and fAPAR were computed, where the fraction of absorbed red radiation was used as a surrogate for fAPAR. Regressions were applied to measured and simulated data to describe general VI-LAI and VI-fAPAR relations. In each regression using canopy reflectances, LAI, solar zenith angle, and leaf angle distribution varied while view angle was held constant.

Correlation coefficients and slopes from the regression equations using measured and simulated data werc
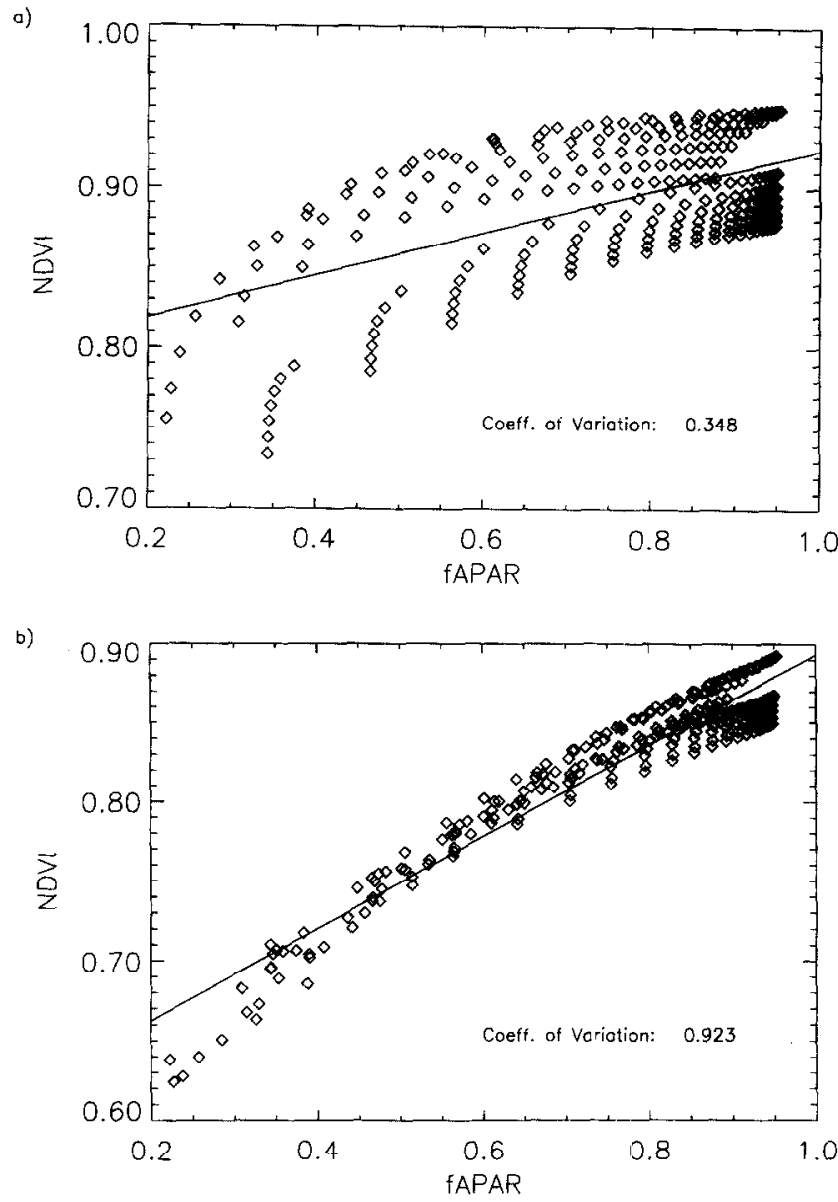

Figure 13. NDVI as a function of fAPAR for the (a) lowest correlation case of Figure 12a (i.e., from the forward scatter direction) and (b) highest correlation case of Figure 12a.

plotted as functions of view zenith and azimuth angle. Linear relations from vegetation indices derived from bidirectional reflectance of alfalfa and similar canopies were used to further investigate the sensitivity of relations to LAI and fAPAR.

\section{RESULTS AND DISCUSSION}

\section{Experimental}

Mean tilt angles in canopies dominated by leaves typically ranged between $56^{\circ}$ and $62^{\circ}$, indicating little change in leaflet zenith angle during the morning hours (no data are available on the azimuthal dependency of the mean tilt angle). However, diaheliotropy is most pronounced at large $\theta_{s}$ (Moran et al., 1989) and was visually obvious in this study for $\theta_{s}$ greater than $35^{\circ}$. Alfalfa mean tilt angle progressed from near vertical after cutting to about $50^{\circ}$ from the horizontal when mature, an indication of stem dominance in early growth.

Results of leaflet optical measurements showed hemispherical PAR reflectance factors to be statistically different bctwecn adaxial and abaxial leaflet surfaces. Average 
PAR absorptance was $88 \%$ for adaxial surfaces and $83 \%$ for abaxial surfaces [similar values were reported by Walter-Shea et al. (1991) for soybean and corn]. SE-590 data showed that abaxial reflectances were higher than adaxial reflectances across all measured wavelengths, particularly in the green and red regions. Average NIR absorptance was $12 \%$ for adaxial and abaxial surfaces. Upper canopy leaf reflectance and transmittance were higher in the middle of the experimental period than they were at the beginning and end of the period. This resulted in variations of $3-5 \%$ (absolute) in mean PAR reflectance and transmittance during the experiment.

The alfalfa was harvested on three dates [day of year (DOY) 155 (4 June), 192 (11 July), and 234 (22 August)] and was irrigated after the first cutting. LAI varied from 0.4 to 4.7 among measurement dates (Fig. 1). Soil moisture ranged from $20 \%$ to $27 \%$ on days of BRF measurements (DOY 267 and 173, respectively). Munsell color of the soil change little on the days of measurement, varying from a very dark grayish brown $(2.5 \mathrm{Y} 3 / 0)$ at $27 \%$ gravimetric water content to a grayish brown (2.5Y 5/2) at $20 \%$ water content. Subsequently, changes in measured reflectance as a result of soil moisture differences were minimal. The fraction of absorbed photosynthetically active radiation decreased with decreasing solar zenith angle and LAI, consistent with Pinter (1993) (Fig. 2).

The number of solar zenith angles represented on a particular day was dependent on time of year and sky condition. At least three morning $\theta_{s} s$, including solar noon $\left(55^{\circ}, 45^{\circ}\right.$, and $\left.43^{\circ}\right)$ and at most five morning $\theta_{s} \mathrm{~s}$, including solar noon $\left(55^{\circ}, 45^{\circ}, 35^{\circ}, 25^{\circ}\right.$, and $\left.18^{\circ}\right)$ were represented. Thus, $\theta_{s} \mathrm{~s}$ were not equally represented (i.e., solar zenith angle treatments have different sample sizes), with as many as 16 days for $45^{\circ} \theta_{\mathrm{s}}$ and as few as 8 days for solar noon $\theta_{s}$ with LAI ranging from 0.5 to 4.7 on these days.

\section{General Trends in Canopy Reflectances and Vegetation Indices: Measured}

The vicw zenith angle at which minimum and maximum values of red and NIR BRFs were obtained varied with $\theta$, and LAI (Fig. 3). Minimum values were generally obtained at a view in the forward scatter direction, whereas maximum values were obtained in the backscatter direction. Similar trends have been reported elsewhere for alfalfa (Epiphanio and Huete, 1995; Kirchner et al., 1982); corn (Ranson et al., 1985); soybean and turf (Deering and Eck, 1987); and native grasses (Deering et al., 1992; Walter-Shea et al., 1992). In addition, similar trends were observed in the simulated data, as exemplified with simulation at LAI of 1.4 and solar zenith angle of $45^{\circ}$ (corresponding to DOY 212) (Fig. 4). The measured leaf angle distribution was used in DISORD (not the simplified planophile/erectophile values). A solar zenith angle of $45^{\circ}$ was chosen because it is the most common $\theta_{s}$ measurement in the experiment and is in accord with the
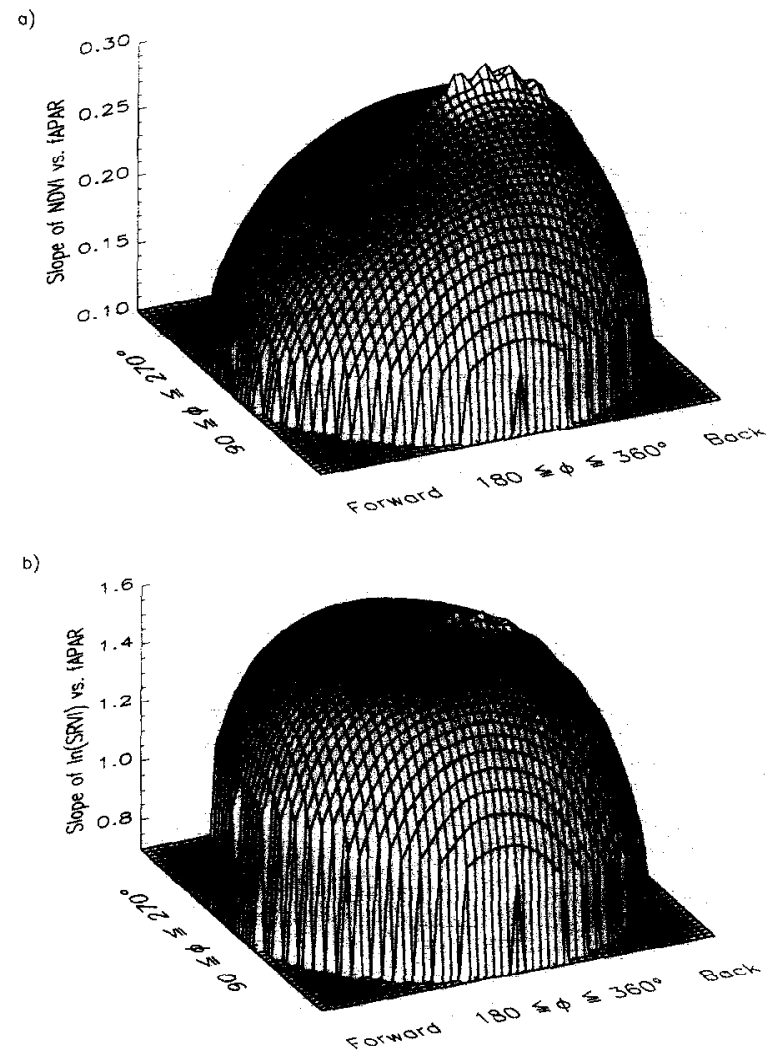

Figure 14. Sensitivity of the simulated vegetation indices with FAPAR as a function of viewing geometry. The sensitivity is indicated by the slopes of the regression lines. View zenith angles increase from the center (nadir) outward to the edge $\left(75^{\circ}\right.$ ). The backscalter angles are loward the right. For each view angle, LAI varied between 0.5 and 5.0 by intervals of 0.25 , the solar angle varied between $0^{\circ}$ and $65^{\circ}$ by $5^{\circ}$ intervals, and the leaf angle distribution varied between erectophile and planophile. (a) NDVI vs fAPAR. (b) $\ln$ (SRVI) vs fAPAR.

recommendation of Middleton (1991). The measured and simulated data agreed with RMSE of $1.6 \%$ in red and $3.9 \%$ in NIR and further demonstrate that red and NIR reflectance vary with sun-target-sensor geometry. A hot spot (i.e., the backscatter in the $\theta_{v}$ proximity equal to $\theta_{*}$ ) was prominent in the simulated data but was less pronounced in the experimental data, because measured values were not corrected to compensate for the shadow cast by the MMR. Agreement between experimental and simulated data also indicates that the effects due to diaheliotropism and leaf optical properties differences were minimal.

Differences in response of NDVI and SRVI indicate unique relations for each view geometry (Fig. 5). Generally, NDVI and SRVI increased in magnitude from far backscattering to far forward scattering at moderate to large LAI. Maximum values were obtained near $20^{\circ}$ and $30^{\circ}$ in the forward scattering direction. Similar results have been reported for native grassland species (Brown de Coulston et al., 1995; Deering and Middleton, 1990) and alfalfa (Epiphanio and Huete, 1995). Response dif- 
a)

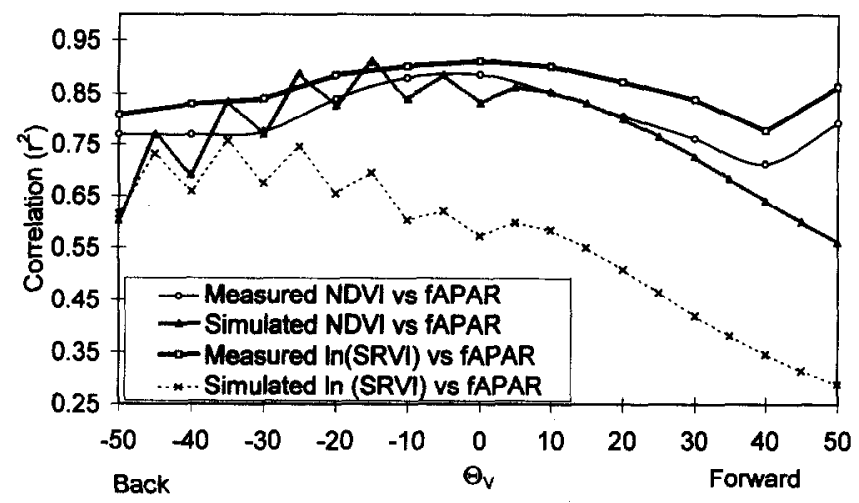

b)

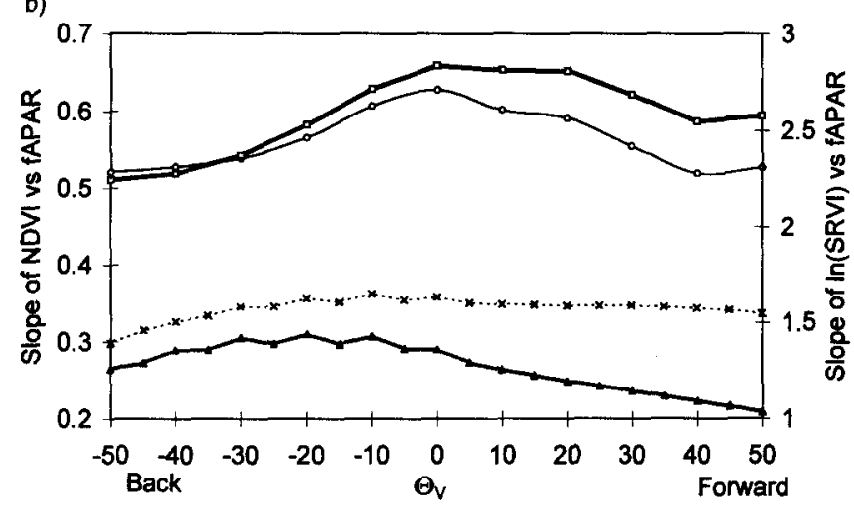

Figure 15. Regression results for NDVI vs fAPAR and $\ln ($ SRVI) vs fAPAR calculated from measured BRFs and simulated results (from Figs. 12 and 14) as a function of viewing geometry in the solar principal plane. View zenith angles range from nadir to $50^{\circ}$ in the backscatter and forward scatter directions. For each view angle for measured BRF values, LAI varied between 0.4 and 4.7 , and the solar angle varied between $18^{\circ}$ and $55^{\circ}$. All combinations were used for each regression. (a) Correlation coefficients $\left(r^{2}\right)$. (b) Slopes.

ferences are attributed to reflectance changes in the red and NIR due to $\theta_{s}, \theta_{v}$, and LAI (i.e., because red is more responsive to sunlit and shadowed parts of the canopy than is NIR) and to indices formulation (i.e., low values of red reflectance have a major effect as the denominator of the SRVI but little effect on the NDVI). At low to moderate LAI, the distributions as functions of $\theta_{v}$ tended to be bimodal with low values near the nadir view, where soil is most visible. Similar trends have been reported for a prairie grassland of moderate LAI (Deering and Middleton, 1990). NDVI and SRVI increased with increasing LAI. However, the NDVI response with respect to solar and view zenith angles became less variable with increasing LAI, whereas the opposite occurred for SRVI. Goward and Huemmrich (1992) found similar trends between simulated NDVI and LAI data.

\section{Relations between Vegetation Index and LAI: Measured and Simulated}

The relations between measured NDVI and LAI from solar principal plane data was curvilinear (asymptotic) and varied according to $\theta_{s}$ and $\theta_{v}$ treatments (Fig. 6a), attributed to the fact that total LAI is considered constant through a day, whereas NDVI is a function of $\theta_{s}$ and $\theta_{v}$. Middleton (1991) reports that VI values respond to the instantaneously projected, illuminated, green LAI; that is, VI values are more related to the projected LAI than to the invariant absolute vertical LAI. Variation in LAI across the experimental field (as large as one LAI unit for canopies of $\mathrm{LAI} \geqslant 4$ ) and changing leaf optical properties through the experimental period probably contributed to scatter beyond the smoothed lines.

The relations between LAI and SRVI were predominantly linear but varied according to $\theta_{\mathrm{s}}$ and $\theta_{\mathrm{v}}$ in particular (Fig. 6b). The variation increased as SRVI increased with LAI. The hot-spot effect and soil contributions may contribute to the scatter because they are dependent on $\theta_{\mathrm{s}}$ and affect the SRVI (see Fig. $5 \mathrm{~b}$ ).

The regression models used for relating NDVI and SRVI to LAI took the following forms:

$$
\begin{gathered}
\mathrm{NDVI}=\beta_{0}+\beta_{1} \cdot \ln (\mathrm{LAI}) ; \\
\mathrm{SRVI}=\beta_{0}+\beta_{1} \cdot \mathrm{LAI} .
\end{gathered}
$$

The linearity results for VI-LAI relations from the simulated data (Fig. 7) indicated that indices from forward scattering angles were less correlated with LAI under variable solar $\left(0^{\circ}<\theta_{s}<65^{\circ}\right)$ and leaf angle distribution (planophile and erectophile) conditions than were those from backscattering angles. This may be caused by significant changes in NIR reflectance $(8 \%$ absolute) at some forward view angles when the solar angle is varied and when the corresponding change in red reflectance is minimal under these conditions (Fig. 3). Note that for maximum correlation with LAI, red and NIR reflectance must change by the same relative amounts when solar or leaf angles are changed. At moderate view angles (approximately $50^{\circ}$ ) in the backscatter direction, red and NIR reflectance increased with increasing solar angle. The result was that the highest correlations occurred in the hackscatter position [as noted by Roujean and Breon (1995) in their modeling study] at about $30^{\circ}$ view zenith, but about $10^{\circ}$ azimuth from the solar principal plane. Hot-spot effects may prevent the maximum values from being reached on the solar principal plane. Correlations decreased in all directions away from the maxima, with the minimum values at large forward scattering angles. In general, correlations were low at all large view zenith angles.

The sensitivity of VI values to LAI is indicated by the slope of the regression lines (Fig. 8). Sensitivity results for NDVI relations to $\ln (\mathrm{LAI})$ largely followed the trends for the correlations. The maximum values were at moderate view zenith angles in the backscatter direction (at approximately $45^{\circ}$ ) and the lowest values were at large view zenith angles, particularly in the forward scattering direction. In essence, NDVI was most sensitive to 


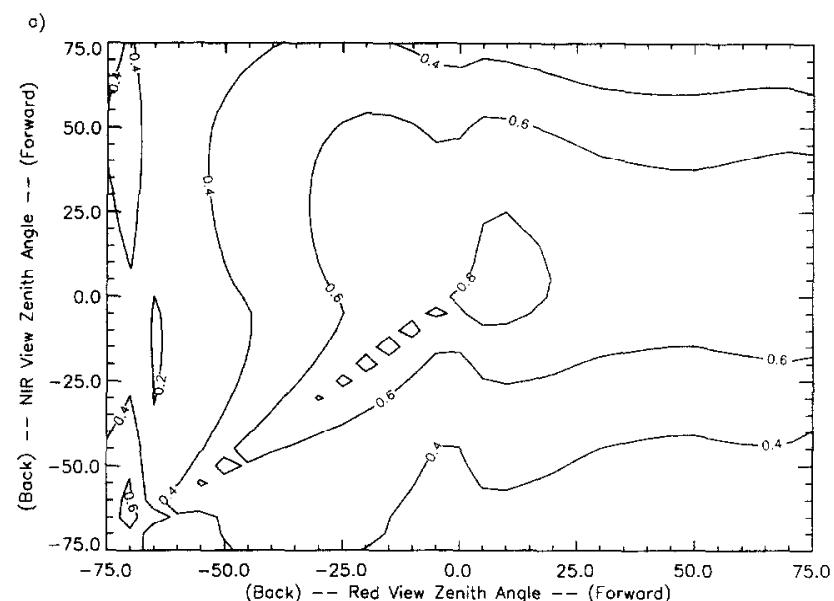

b)

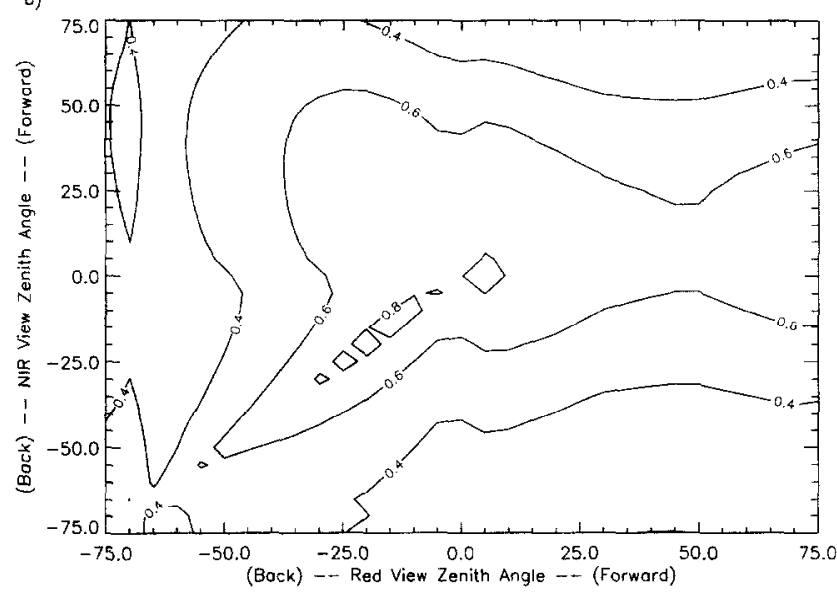

Figure 16. Correlation coefficient $\left(r^{2}\right)$ of vegetation indices calculated from simulated BRFs with fAPAR when indices are formed from different red and NIR viewing angles. For each view angle combination, LAI varied between 1,3 , and 5 , the solar angle varied between $0^{\circ}$ and $65^{\circ}$ by $5^{\circ}$ intervals and the leaf angle distribution varied between erectophile and planophile. All combinations were used in each regression. (a) NDVI vs fAPAR. (b) $\ln ($ SRVI) vs fAPAR.

LAI in the same directions in which it was most correlated. The trends in the SRVI-LAI sensitivity plot, however, were markedly different from those for the correlation plot. Specifically, the maximum sensitivity was at large forward scattering angles, and sensitivity decreased with decreasing view zenith angle owing to relatively little change in red and NIR at these angles, as indicated by measured data (see Fig. 3). Thus, SRVI was much less sensitive to LAI in the directions where it is most linearly correlated.

Vegetation indices (derived from measured alfalfa canopy reflectances) were also correlated with LAI as a means of testing the applicability of the simulation results. Although trends in the measured data (Fig. 9) were not as pronounced as those for the simulated results, they, in most cases, were consistent with those found with the simulated data (see also Figs. 7 and 8). Results
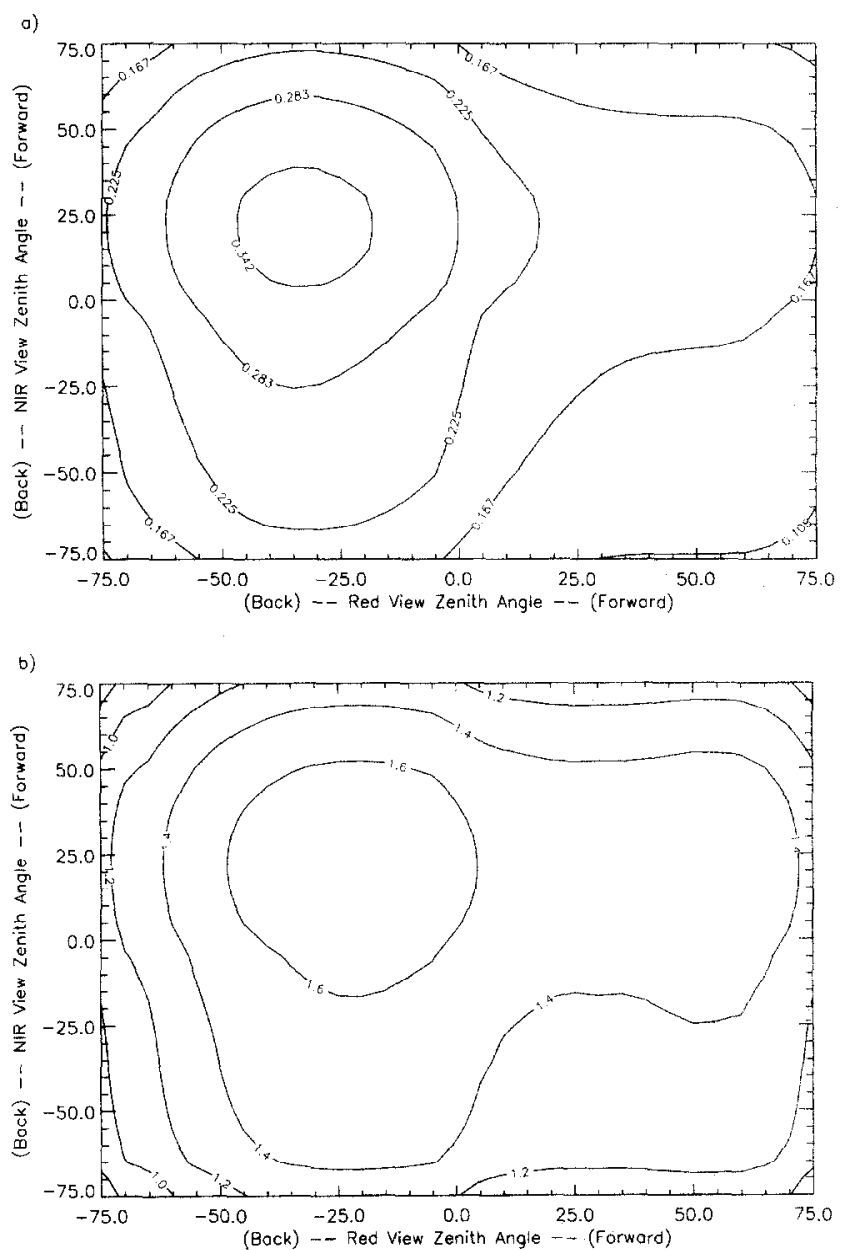

Figure 17. The sensitivity of simulated vegetation indices to fAPAR. The sensitivity is indicated by the slopes of the regression lines. For each view angle combination, LAI varied between 1,3 , and 5 , the solar angle varied between $0^{\circ}$ and $65^{\circ}$ by $5^{\circ}$ intervals, and the leaf angle distribution varied between erectophile and planophile. (a) NDVI vs fAPAR. (b) $\ln$ (SRVI) vs fAPAR.

from measured NDVI-ln(LAI) correlations indicate a maximum near the $20^{\circ}$ backscatter direction while no clear trend with view angle was observed for measured SRVI-LAI correlations; maximum correlations occurred at moderate backscatter angles with simulated data. The trends in the sensitivity of the measured VI-LAI relations were very similar to the trends indicated with the simulations (Fig. 9). The maximum sensitivity of NDVI to LAI was at small backscatter angles (approximately $10^{\circ}$ ), whereas the maximum sensitivity of SRVI to LAI was at medium forward scatter angles. Differences between the measured and simulated relations with view angle are attributed to the fact that the ranges of solar, view, and leaf angle conditions simulated with the model greatly exceed those for the field data (where: $18^{\circ}<\theta_{s}<55^{\circ}$, $0^{\circ}<\theta_{s}<50^{\circ}$ in the backscatter and forward scatter directions; and $56^{\circ}<$ mean leaf angle $<62^{\circ}$ ). 
)
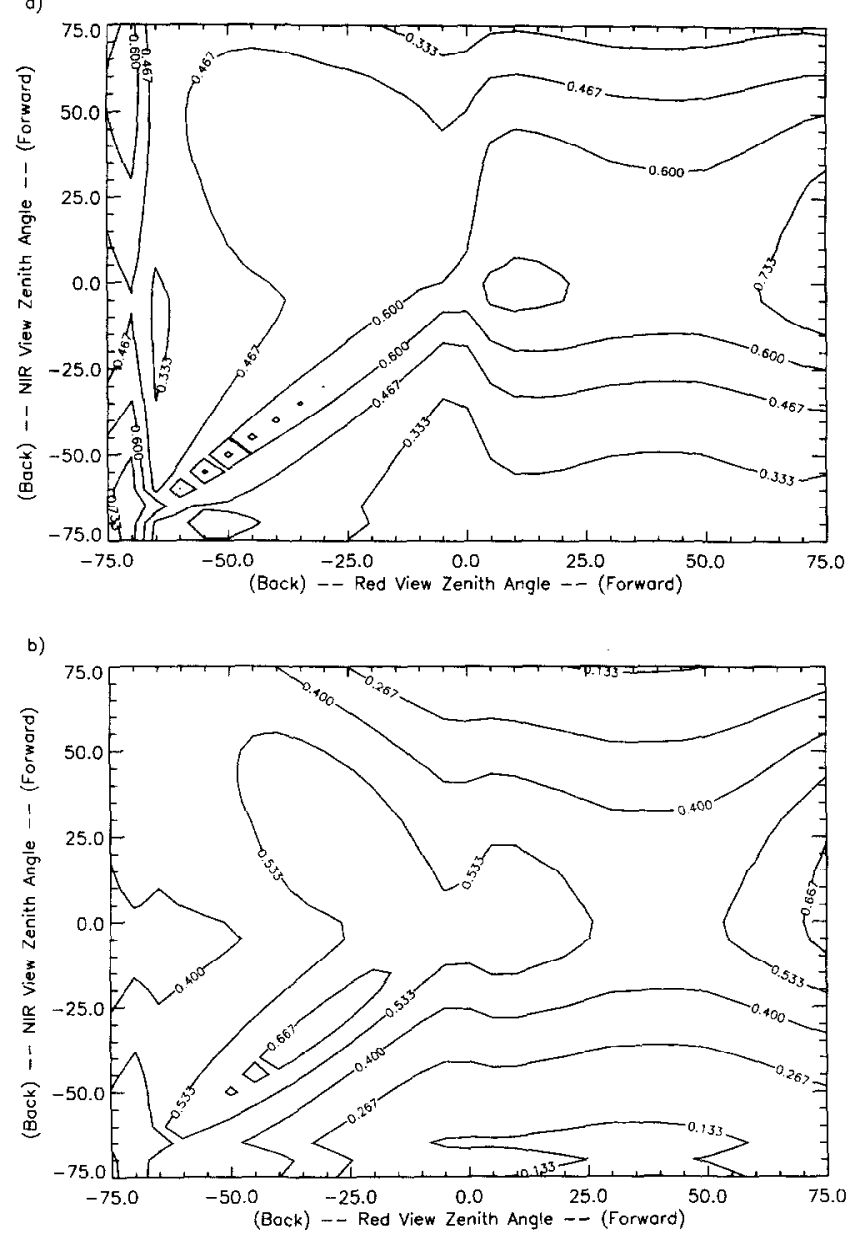

Figure 18. Correlation coefficient $\left(r^{2}\right)$ of vegetation indices calculated from simulated BRFs with LAI when indices are formed from different red and NIR viewing angles. For each view angle combination, LAI varied between 1,3 , and 5 , the solar angle varied between $0^{\circ}$ and $65^{\circ}$ by $5^{\circ}$ intervals, and the leaf angle distribution varied between erectophile and planophile. (a) NDVI vs $\ln (\mathrm{LAI})$. (b) SRVI vs LAI.

\section{Relations between Vegetation Indices and fAPAR: Measured and Simulated}

The relation between NDVI and fAPAR derived from measured BRFs varied (Fig. 10a). Generally, NDVIs in the backseatter direction were linearly related to fAPAR, indicating that NDVIs at these geometries increased with $\theta_{s}$ in a similar manner as fAPAR. NDVIs at oblique forward scatter angles were less linearly related to fAPAR than were those from the backscatter direction. Similar nonlinearity between fAPAR and NDVI derived from BRFs acquired at oblique view angles by using canopy radiative transfer models has been noted by others (Asrar et al. 1992; Goward and Huemmrich, 1992; Roujean and Breon 1995). Scatter decreased with increasing fAPAR, because NDVI approached its asymptotic limit.

Compared with NDVI, there was less scatter in the measured SRVI-fAPAR relation at low fAPAR, although scatter increased as fAPAR increased (Fig. 10b), contrib- uting to the exponential relation. SRVI assumed an exponential relation with CAPAR for all $\theta_{s}$ and $\theta_{v}$, similar to the relation between LAI and FAPAR (Fig. 11). This is not surprising, becausc SRVI was near-linearly rclated to LAI for these canopies (see Fig. 6b).

On the basis of these results, the regression models used for relating fAPAR to NDVI and SRVI took the following forms:

$$
\begin{gathered}
\mathrm{NDVI}=\beta_{0}+\beta_{1} \cdot \mathrm{fAPAR} ; \\
\ln (\mathrm{SRVI})=\beta_{0}+\beta_{1} \cdot \mathrm{fAPAR} .
\end{gathered}
$$

Regression results for fAPAR from the simulated data indicated that the indices from the forward scattering directions were less correlated with fAPAR than were those from the backscatter direction, particularly those from small zenith angles (Fig. 12). Measured and simulated data (see Figs. 3 and 4 ) showed only 2 to $5 \%$ (absolute) of red radiation was scattered forward regardless of canopy and solar parameter values. Yet measured data showed that fAPAR changed significantly with changes in these parameters. Because absorbed red radiation is a component of fAPAR (NIR is not), this implies that forward geometries contributed relatively little to the change in FAPAR, as indicated by simulations (Fig. 13a). In contrast, indices at small zenith angles in the backscattering directions were highly correlated with FAPAR (Fig. 13b) where an increasing change in VI occurred as fAPAR increased (see Figs. 2 and 5). However, the NDVI-fAPAR correlation fell off markedly at large view zenith angles (see Fig. 12). Overall, simulated data indicated that solar principal plane geometries were less correlated with fAPAR than were nonprincipal plane geometries. This is attributed to hot-spot effects, which are spectrally dependent.

The sensitivity plots showed slightly different trends between the two simulated indices (Fig. 14). The NDVI sensitivity plot was similar in shape to the correlation plot; NDVIs in the solar principal plane at small backscatter angles were the most sensitive to fAPAR. However, the range of slopes was much larger than the range of slopes in the sensitivity plot for LAI. Although SRVIs from small harkscatter angles were most sensitive to fAPAR (as with NDVI), SRVIs at forward scatter angles also were sensitive, as well as those at other nonsolar principal plane angles. Again, the range of sensitivity values was much larger for fAPAR than for LAI.

Vegetation indices (derived from measured alfalfa canopy reflectances) were correlated with fAPAR as a means of testing the applicability of the VI-fAPAR simulation results. Trends in the measured data were not as pronounced as those for the simulated results; but, as in the VI-LAI results, they, in most cases, were similar to those found with the simulated data (Fig. 15). The measured VI-fAPAR correlation values clearly depict the maximum near nadir and at small backscatter angles 

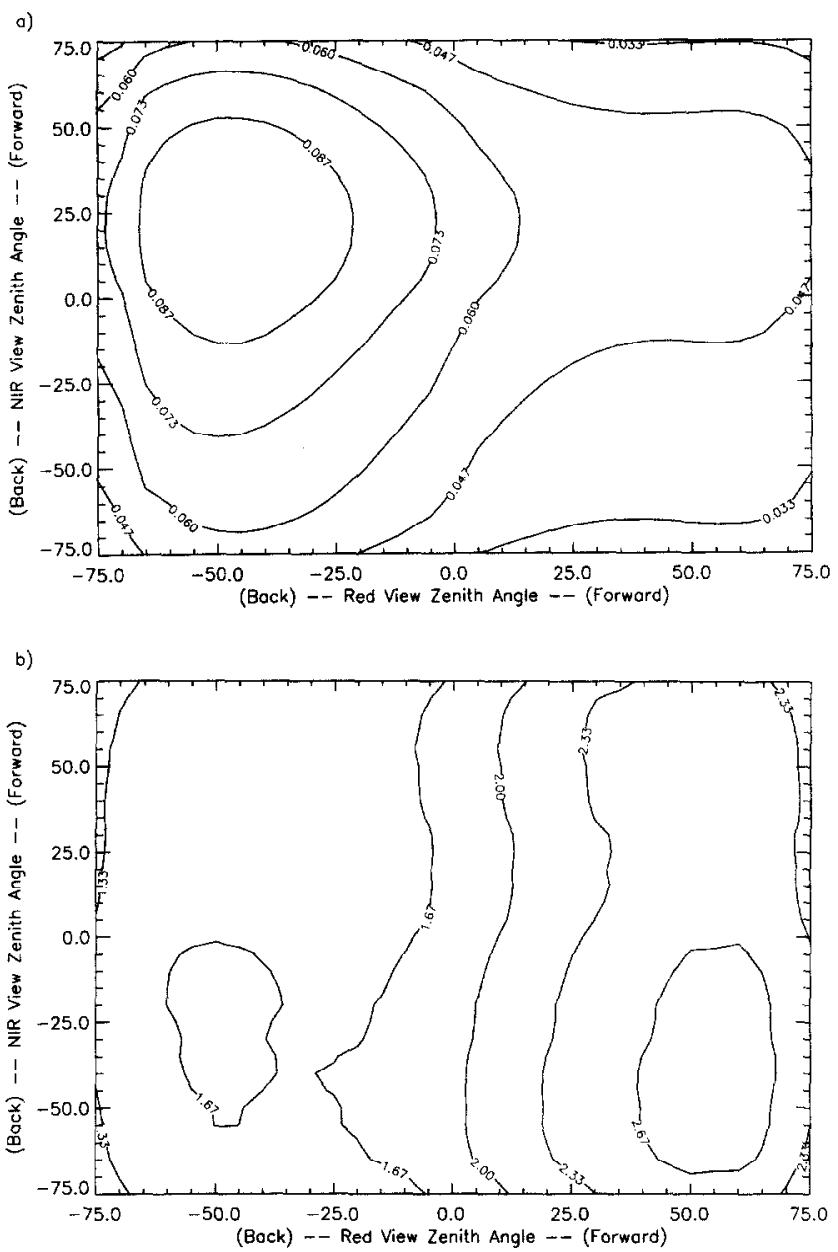

Figure 19. The sensitivity of simulated vegetation indices to LAI. The sensitivity is indicated by the slopes of the regression lines. For each view angle combination, LAI varied between 1,3 , and 5 , the solar angle varied between $0^{\circ}$ and $65^{\circ}$ by $5^{\circ}$ intervals, and the leaf angle distribution varied between erectophile and planophile. (a) NDVI vs $\ln$ (LAI). (b) SRVI vs LAI.

while the maximum correlations using simulated data occurred at moderate backscatter directions $\left(15-30^{\circ}\right)$. The maximum sensitivity of measured NDVI to fAPAR was at near-nadir angles while the maximum sensitivity of $\ln$ (SRVI) to f $\Lambda$ PAR was over a broad zenith range around nadir extending into the forward direction. Results using simulated data indicated maximum sensitivities in small backscatter directions (approximately 10-20 $0^{\circ}$. Differences between the measured and simulated relations with view angle are attributed, as in VILAI relations, to the fact that the ranges of solar, view, and leaf angle conditions simulated with the model greatly exceed those for the field data.

These results show that the careful selection of view geometries and regression formulation can greatly affect the success of VIs. The angles of maximum correlation between NDVI and FAPAR were at smaller view zenith angles than were the angles of maximum correlation be- tween NDVI and $\ln (\mathrm{LAI})$, whereas the maximum correlations between $\ln$ (SRVI) with FAPAR and SRVI with LAI were similar. The range of correlation coefficients for NDVI-fAPAR was greater than that for NDVI-In(LAI). Qualitatively, the NDVI and SRVI correlation relations were similar hetween I.AI and fAPAR. In general, the higher sensitivity of indices to fAPAR, compared with LAI, was expected because fAPAR is the complement of canopy reflectance for dense canopies. In essence, both indices and FAPAR are radiation quantities, whereas LAI is nonlinearly related to radiation. By choosing remote sensing samples at angles shown to have high correlation, one may assume solar angle and leaf angle effects are minimal.

\section{Vegetation Indices from Dissimilar Simulated Red and NIR Reflectance Geometries: Simulated}

The foregoing results showed that change in reflectance caused by changes in canopy condition depended on both the sampling geometry and reflectance wavelength. Thus, it is possible that constructing VIs with red and NIR reflectance from different geometries may produce improved VI behavior. Although most satellites sample a target from a single geometry for a given pass, satellite vegetation studies routinely use data collected in 10- to 30-day periods to determine composite VI values (Cihlar et al., 1994). Because some remote sensing systems (e.g. NOAA AVHRR) collect at least one sample per target per day, a large collection of geometries may be available over compositing periods. Traditionally, and in the preceding sections, the red and NIR reflectances used to create the composite VIs are from a single view angle. This requirement has been relaxed in the discussion that follows, and VIs were formed with reflectances from different view angles. Specifically, NDVI and SRVI were calculated by using all geometric combinations of simulated red and NIR reflectance from principal plane angles. Regression models (as defined in the preceding section) were applied to describe the VI-fAPAR and VILAI relations, where solar angle and leaf angle distribution varied as before. To reduce the computational expense, only LAIs of 1,3 , and 5 were used.

The correlation of NDVI with fAPAR (Fig. 16a) suggests that the relation was most linear when NDVI was calculated with red and NIR values from the same view angle in the near-nadir or backscatter direction. In fact, the VIs derived from near-nadir angles had the highest correlation. Because existing NDVI compositing methods attempt to choose view angles close to nadir, relatively favorable NDVI-fAPAR relations are probably realized when only solar principal plane data are available. Interestingly, the correlations were most sensitive to NIR view angle; that is, the contour lines in Figure 16a were nearly parallel to the red reflectance axis at forward view angles. From canopy reflectance measurements (see Fig. 
3), NIR reflectance at nadir was relatively invariant $(<10 \%$ relative change) to solar angle while red reflectance varied by approximately 33\% (relative), suggesting that the correlation depcnded largely on the sensitivity of red reflectance to changes in solar angle and canopy LAI. This sensitivity was greatest at small forward view angles, especially at moderate to high LAI (see Fig. 3). In fact, it appears that NIR reflectance sensitivity to solar angle had a negative effect (backscatter direction). At large $\theta_{v}$, red and NIR changed little with $\theta_{s}$ and thus was not sensitive to diurnal fAPAR changes (whereas fAPAR is dependent on $\theta_{s}$ ). The $\ln (\mathrm{SRVI})$-fAPAR results (Fig. 16b) were very similar to those for NDVI-fAPAR in pattern as well as in magnitude.

The sensitivity plots (Fig. 17) differed from those for correlation. The maximum sensitivity of NDVI to fAPAR and of $\operatorname{In}(\mathrm{SRVI})$ to fAPAR occurred by combining middle backscatter samples from the red band with middle forward scattering angles for the NIR. The least-sensitive combinations were from high forward angles for red and high backscatter angles for NIR.

The correlation of the VIs with LAI (Fig. 18) were slightly lower than the correlations with fAPAR but were significant in some cases. The SRVI-LAI and NDVI$\ln (\mathrm{LAI})$ results (Fig. 18) suggested that the correlation with LAI was greatest when the red and NIR reflectances are gathered at the same backscatter directions, especially at moderate to slightly forward angles. This is consistent with trends noted in the preceding section. From the measured data, both bands are indeed more sensitive to LAI in backscatter directions (see Fig. 3). The large forward view angles for red, combined with near-nadir angles for NIR, also lead to high correlation.

Finally, the sensitivity plots for the NDVI-ln(LAI) relation (Fig. 19) were very similar to the sensitivity plots for VI-fAPAR. Specifically, an NDVI determined with middle backscatter red reflectance and near-nadir NIR reflectance in the forward scatter direction was most sensitive to $\ln (\mathrm{LAI})$. This is consistent with measured data; both bands become increasingly sensitive to LAI while relatively invariant to $\theta_{t}$ in these directions (see Fig. 3). In contrast, an SRVI determined with high forward scatter red reflectance and middle backscatter NIR reflectance was most sensitive to $\ln (\mathrm{LAI})$. Although Figure 3 suggests that red reflectance is much less sensitive to LAI at these angles than at other principal plane angles, the NIR reflectance clearly becomes more sensitive to I.AI as the backscatter angle increases. The changes in NIR reflectance with LAI greatly exceeded those in red reflectance. In general, this suggests that NDVI was more dependent on the red reflectance behavior, whereas SRVI was more dependent on the NIR reflectance behavior. This conclusion is consistent with earlier results showing that SRVI saturated at larger LAI than did NDVI (see Fig. 6), because NIR reflectance saturated at a higher LAI than did red reflectance. Note that the sensitivities for NDVI-ln(LAI) relations were four times less than those for the NDVI-fAPAR relations, whereas the sensitivities for the $\ln$ (SRVI)-fAPAR and SRVI-LAI relations were similar, supporting recent studies (Sellers et al., 1992) that show that fAPAR is the variable most related to vegetation indices.

\section{SUMMARY AND CONCLUSIONS}

Results indicate the possible effects of sun and view direction on reflected signals and vegetation indices as well as on relations between vegetation indices and biophysical parameters as alfalfa and similar crops develop. Reflected visible (red) radiation is affected by shadows much more than NIR radiation, so the NDVI and SRVI acquired in the forward scatter direction were higher in value than those acquired in the backscatter direction and changed with $\theta_{s}$ and $\theta_{v}$. Sun-view geometry effects resulted in variations as large as 2 units of LAI and 0.3 units of fAPAR when compared with empirical relations. Variation in NDVI decreased as LAI increased, whereas SRVI variation increased as LAI increased. Whereas relations between LAI and NDVI were curvilinear, those between LAI and SRVI were nearly linear. FAPAR was linearly related to NDVI derived from data acquired near the backscatter position. This relation fails at oblique views and in the forward scatter direction. SRVI was nonlinearly related to fAPAR. The applicability of bidirectional linear and exponential estimators to estimate these biophysical parameters with minimal dependence on solar angle and leaf angles was demonstrated. However, in general, VIs were more sensitive to fAPAR than LAI, attributed to the fact that FAPAR is a radiation quantity, whereas LAI is nonlinearly related to radiation. The variation noted in the relations varied more with view angle than with illumination angle.

Results show that careful selection of view geometries can greatly affect the success of VIs. Combinations of red and NIR reflectances form the solar principal plane to form BRF VIs suggest that NDVI and SRVI in the near-nadir or backscatter direction give the highest correlation yet not the highest sensitivity (results were similar to VIs derived from red and NIR BRFs from the same viewing geometry). Further exploration into BRF VIs is encouraged. However, because existing NDVI compositing methods are designed to choose view angles close to nadir, relatively favorable NDVI-fAPAR relations are probably being acquired. Although vegetation indices from forward angles were shown to be least optimal, it has been suggested that they can be preferentially chosen in some compositing routines (Goward et al., 1993). In cases where compositing routines invert simple bidirectional reflectance models to predict NDVI at a standard angle (often nadir), we suggest that the routines be changed to use a standard angle most correlated with the desired parameter (often nonnadir). 
Research regarding VIs should be directed toward understanding (1) the variation within various ecosystenıs (natural and managed) in relations between off-nadir obscrvations and canopy attributcs such as LAI and FAPAR and (2) the usefulness of remote sensing observations at various illumination and viewing geometries in extracting canopy attributes. The latter research effort could be accomplished through model inversion. Goward and Huemmrich (1992) suggested that a set of relations be derived between remotely sensed observation and canopy attributes as functions of sun and view angles and that these relations be used as a means of predicting LAI and fAPAR. Because the sun-view effect cannot be ignored, research regarding the usefulness of BRFs or the elimination of these effects on reflectance signals should be continued.

We acknowledge the assistance of the UNL's Agronomy Department, particularly Russell Person, for permitting use of the alfalfa field and for patiently working with us in implementing the experiment. The modeling work was supported by a NASA EOS/IDS grant ( $R$. Dickinson, $P I)$ and the MODIS/MODLAND effort (C. Justice, PI). This support is gratefully appreciated. We also thank those who reviewed the manuscript

\section{REFERENCES}

Asrar, G., Fuchs, M., Kanemasu, E. T., and Hatfield, J. L. (1984), Estimating absorbed photosynthetic radiation and leal area index from spectral rellectance in wheat. Agron. J. $76: 300-306$.

Asrar, G., Myneni, R. B., and Choudhury, B. J. (1992), Spatial heterogeneity in vegetation canopies and remote sensing of absorbed photosynthetically active radiation: a modeling study. Remote Sens. Environ. 41:85-103.

Bartlett, D. S., Whiting, G. J., and Hartman, J. M. (1990), Use of vegetation indices to estimate intercepled solar radiation and net carbon dioxide exchange of a grass canopy. Remote Sens. Environ. 30:115-128.

Bonan, G. B. (1995), Land-atmosphere interactions for climate systems models: coupling biophysical, biogeochemical, and ecosystems dynamical processes. Remote Sens. Environ. 5]: $57-73$.

Bouman, B. A. M. (1992), Accuracy of estimating the leaf area index from vegetation indices derived from crop reflectance characteristics: a simulation study. Int. J. Remote Sensing 13:3069-3084.

Brown de Coulston, E. C., Walthall, C. L., Russell, C. A., and Irons, J. R. (1995), Estimating the fraction of absorbed photosynthetically active radiation $\left(\mathrm{f}_{\mathrm{APAR}}\right)$ at FIFE with airborne bidirectional spectral reflectance data. J. Geophys. Res. 100(D12):25,523-25,535.

Chehbouni, A., Kerr, Y. H., Qi, J., Huete, A. R., and Sorooshian, S. (1994), Toward the development of a multidirectional vegetation index. Water Resour. Res. 30:1281-1286.

Choudhury, B. J. (1987), Relationships between vegetation indices, radiation absorption, and net photosynthesis evaluated by a sensitivity analysis. Remote Sens. Environ. 22:209-233.
Cihlar, J., Manak, D., and Voisin, N. (1994), AVHRR bidirectional reflectance effects and compositing. Remote Sens. Environ. 48:77-88.

Deering, D. W., and Eck, T. F. (1987), Atmospheric optical depth effects on angular anisotropy of plant canopy reflectance. Int. J. Remote Sens. 8:893-916.

Deering, D. W., and Middleton, E. M. (1990), Spectral bidirec tional reflectance and effects on vegetation indices for a prairie grassland. In Proe of the Am. Meteorol. Soc. Symp. on FIFE, pp. 71-76, 7-9 February, Anaheim, CA.

Deering, D. W., Middleton, E. M., Irons, J. R., Blad, B. L. Walter-Shea, E. A., Hays, C. J. Walthall, C., Eck, T. F. Ahmad, S. P., and Banerjee, B. P. (1992), Prairie grassland bidirectional reflectances measured by different instruments at the FIFE site. J. Geophys. Res. 97:18,887-18,903.

Duggin, J. J.. Piwinski, D., Whitehead, $V$, and Ryland, $C$ (1982), Evaluation of NOAA-AVHRR data for crop assessment. Appl. Opt. 21:1873-1875.

Epiphanio, J. C. N., and Huete, A. R. (1995). Dependence of NDVI and SAVI on sum-sensor geometry and its effect on fAPAR relationships in alfalfa. Remote Sens. Environ. 51 : 351-360.

Gallo, K. P., Danghtry, C. S. T., and Baner, M. F. (1985) Spectral estimation of absorbed photosynthetically active radiation in corn canopies. Remote Sens. Enciron. 17:221-232.

Goel, N. S., and Strebel, D. E. (1984), Simple beta distribution representation of leaf orientation in vegetation canopies. Agron. J. 76:800-802.

Goward, S. N., Dye, D. G., Turner, S., and Yang, J. (1993), Objective assessment of the NOAA global vegetation index data product. Int. J. Remote Sens. 14:3365-3394.

Goward, S. N., and Huemmrich, K. F. (1992), Vegetation canopy PAR absorptance and the normalized difference vegetation index: an assessment using the SAIL model Remote Sens. Environ. 39:119-140.

Gutman. G. G. (1991), Vegetation indices from AVHRR: an update and future prospects. Remote Sens. Environ. 35: 121-136

Holben, B. N., Tucker, C. J., and Fan, C. (1980), Spectral assessment of soybean leaf area and leat biomass: Photo gramm. Eng. Remote Sens. 46:651-656.

Huete, A. R. (1992), Extraction of soil and vegetation parame ters from high resolution bi-directional reflectance spectra. In Proc. IEEE Int. Geosci. Remote Sens. Symp., pp. 752 754, May, 26-29. Houston, TX, IEEE Inc., Piscataway, NJ.

Huete, A. R., Jackson, R. D., and Post, D. F. (1985), Spectral response of a plant canopy with different soil backgrounds. Remote Sens. Environ. 17:37-53

Jackson, R. D., Moran, M. S., Slater, P. N., and Biggar, B. F. (1987), Field calibration of reference reflectance panels. Remote Sens. Environ. 22:145-158.

Jackson, R. D., and Pinter, P. J., Jr. (1986), Spectral response of architecturally different wheat canopies. Remote Sens. Environ. 20:43-.56.

Jacquemoud, S., Baret, F.. and Hanocq, J. F. (1992), Modeling spectral and bidirectional soil reflectance. Remote Sens. Environ. 41:123-132.

Kirchner, J. A., Kimes, D. S., and McMurtrey, J. E., III (1982). Variation of directional reflectance factors with structural changes of a developing alfalfa canopy. Appl. Opt. 21:37663774 . 
Kumar, M., and Monteith, J. L. (1981), Remote sensing of crop growth. In Plants and the Daylight Spectrum (H. Smith, Ed.), Academic Press, London, pp. 133-144.

Middleton, E. M. (1991), Solar zenith angle effects on vegetation indices in tallgrass prairie. Remote Sens. Environ. 38: 45-62.

Moran, M. S., Pinter, P. J., Jr., Clothier, B. E., and Allen, S. G. (1989), Effect of water stress on the canopy architecture and spectral indices of irrigated alfalfa. Remote Sens. Environ. 29:251-261.

Myneni, R. B., Asrar, G., and Hall, F. G. (1992), A threedimensional radiative transfer model for optical remote sensing of vegetated land surfaces. Remote Sens. Environ. 41:85-103.

Nicodemus, F. E., Richmond, J. C., Hsia, J. J., Ginsberg, I. W., and Limperis, T. (1977), Gcometrical considerations and nomenclature for reflectance. NBS Monograph No. 160, National Bureau of Standards, Dept. of Commerce, Washington, D.C. 20234 USA.

Norman, J. M., Welles, J. M., and Walter, E. A. (1985), Contrasts among bidirectional reflectance of leaves, canopies, and soils. IEEE Trans. Geosci. Remote Sens. GE-23:659-667.

Pinter, P. J., Jr. (1993), Solar angle independence in the relationship between absorbed PAR and remotely sensed data for alfalfa. Remote Sens. Environ. 46(1):19-25.

Pinter, P. J., Jr., Zipoli, G., Maracchi, G., and Reginato, R. J. (1987), Influence of topography and sensor view angles on NIR/red ratio and greenness vegetation indices of wheat. Int. J. Remote Sens. 8:953-957.

Privette, J. L., Myneni, R. B., Emery, W. J., and Pinty, B. (1995), Inversion of a soil bidirectional reflectance model for use with vegetation reflectance models. J. Geophys. Res. 100(D12):25,497-25,508

Ranson, K. J., Daughtry, C. S. T., Biehl, L. L., and Bauer, M. E. (1985), Sun-view angle effects on reflectance factors of corn canopies. Remote Sens. Environ. 18:147-161.

Robinson, B. F., and Biehl, L. L. (1979), Calibration procedures for measurement of reflectance factor in remote sensing field research. Proc. Soc. Photo-Opt. Instr. Eng. 196: $16-26$.

Ross, J. K. (1981), The Radiation Regime and Architecture of Plant Stands. W. Junk, The Hague, Netherlands.

Roujean, J.-L., and Breon, F.-M. (1995), Estimating PAR absorbed by vegetation from bidirectional reflectance measurements. Remote Sens. Environ. 51:375-384.
Sellers, P. J. (1985), Canopy reflectance, photosynthesis and transpiration. Int. J. Remote Sens. 6:1335-1372.

Sellers, P. J., Berry, J. A., Collatz, G. J., Field, C. B., and Hall, F. G. (1992), Canoy reflectance, photosynthesis, and transpiration III: a reanalysis using improved leaf models and a new canopy integration scheme. Remote Sens. Environ. 42:187-216.

Sellers, P. J., Rasool, S. I., and Bolle, H.-J. (1990), A review of satellite data algorithms for studies of the land surface. Bull. Am. Meteorol. Soc. 71:1429-1447.

Sellers, P. J., Tucker, C. J., Collatz, G. J., Los, S. O., Justice, C. O., Dazlich, D. A., and Randall, D. A. (1994), A global $1^{\circ}$ by $1^{\circ}$ NDVI data set from climate studies, part 2: the generation of global fields of terrestrial biophysical parameters from the NDVI. Int. J. Remote Sens. 17:3519-3545.

Shibayama, M., Wiegand, C. L., and Richardson, A. J. (1986), Diurnal patterns of bidirectional vegetation indices for wheat canopies. Int. J. Remote Sens. 7:233-246.

Steven, M. D., Biscoe, P. V., and Jaggard, K. W. (1983), Estimation of sugar beet productivity from reflection in the red and infrared spcctral bands. Int. J. Remote Sens. 4:325-334.

Stewart, R. D. (1991), Modeling radiant energy transfer in vegetation canopies. Master's Thesis, Kansas State University, Manhattan, KS.

Travis, R. L., and Reed, R. (1983), The solar tracking pattern in a closed alfalfa canopy. Crop Sci. 23:664-668.

Tucker, C. J. (1979), Red and photographic infrared linear combinations for monitoring vegetation. Remote Sens. Environ. 8:127-150.

Walter-Shea, E. A., Blad, B. L., Hays, C. J., Mesarch, M. A., Deering, D. W., and Middleton, E. M. (1992), Biophysical properties affecting vegetative canopy reflectance and $a b$ surbed photosynthetically aclive radiation at the FIFE site. J. Geophys. Res. 97:18,925-18,934.

Walter-Shea, E. A., Hays, C. J., Mesarch, M. A., and Jackson, R. D. (1993). An improved goniometer system for calibrating field reference-reflectance panels. Remote Sens. Environ. 43:131-138.

Walter-Shea, E. A., Norman, J. M., Blad, B. L., and Robinson, B. F. (1991), Leaf reflectance and transmittance in soybean and corn. Agron. J. 83:631-636.

Wardley, N. W. (1984), Vegetation index variability as a function of viewing geometry. Int. J. Remote Sens. 5:861-870.

Welles, J. M., and Norman, J. M. (1991), Instrument for indirect measurement of canopy architecture, Agron. J. 83: $818-825$. 